\title{
Spectral variability among rocks in Visible and Near Infrared multispectral Pancam data collected at Gusev Crater: Examinations using spectral mixture analysis and related techniques
}

\author{
W.H. Farrand ${ }^{1}$, J.F. Bell III ${ }^{2}$, J.R. Johnson ${ }^{3}$, S.W. Squyres ${ }^{2}$, J. Soderblom ${ }^{2}$, \\ D.W. Ming ${ }^{4}$ \\ 1. Space Science Institute, 4750 Walnut Street, Suite 205, Boulder, \\ Colorado \\ 2. Department of Astronomy, Cornell University, Ithaca, New York \\ 3. United States Geological Survey, Astrogeology Team, Flagstaff, \\ Arizona \\ 4. NASA Johnson Space Flight Center, Houston, Texas
}

\author{
$\underline{\text { Submitted to }}$ \\ JGR Planets \\ Special Issue on MER Spirit \\ May 19, 2005 \\ Revised \\ August 19, 2005
}

Manuscript Pages: 51

Tables: 5

Figures: 20 


\section{Abstract}

Visible and Near Infrared (VNIR) multispectral observations of rocks made by the Mars Exploration Rover Spirit's Panoramic camera (Pancam) have been analysed using a spectral mixture analysis (SMA) methodology. Scenes have been examined from the Gusev crater plains into the Columbia Hills. Most scenes on the plains and in the Columbia Hills could be modeled as three endmember mixtures of a bright material, rock, and shade. Scenes of rocks disturbed by the rover's Rock Abrasion Tool (RAT) required additional endmembers. In the Columbia Hills there were a number of scenes in which additional rock endmembers were required. The SMA methodology identifed relatively dust-free areas on undisturbed rock surfaces, as well as spectrally unique areas on RAT abraded rocks. Spectral parameters from these areas were examined and six spectral classes were identified. These classes are named after a type rock or area and are: Adirondack, Lower West Spur, Clovis, Wishstone, Peace, and Watchtower. These classes are discriminable based, primarily, on near-infrared (NIR) spectral parameters. Clovis and Watchtower class rocks appear more oxidized than Wishstone class rocks and Adirondack basalts based on their having higher $535 \mathrm{~nm}$ band depths. Comparision of the spectral parameters of these Gusev crater rocks to parameters of glass-dominated basaltic tuffs indicates correspondance between measurements of Clovis and Watchtower classes, but divergence for the Wishstone class rocks which appear to have a higher fraction of crystalline ferrous iron bearing phases. Despite a high sulfur content, the rock Peace has NIR properties resembling plains basalts. 


\section{Introduction}

Lithologic diversity can be determined in any one of several ways. In traditional geologic field mapping, color is often used as guide in discriminating between stratigraphic boundaries and as a means of determining if spatially separated outcrops belong to a single formation. In many ways, the Mars Exploration Rover (MER) mission is the first field geology mission to another planet, albeit one that has utilized robotic proxies. Nevertheless, just as a human geologist in the field can use his or her vision to make use of color as an aid to assessing the lithologic diversity of a region, so too, the MER rovers have been able to use the multispectral capabilities of their Panoramic Cameras (Pancams) [Bell et al., 2003; 2004a; 2004b] to assess the color properties of the rocks and soils encountered at the two landing sites [Squyres et al., 2004a,b].

The degree to which multispectral properties in a region vary is referred to as that area's spectral variability. The spectral variability within a multispectral image is related to the number of component surface materials that have distinct spectral reflectance signatures. A high degree of spectral variability is indicative of distinct, spectrally diverse components and potentially of a high degree of lithologic variability. Those components in a scene that are spectrally unique are said to be the spectral "endmembers" of the scene [e.g., Adams et al., 1986]. These spectral endmembers can have a one-toone correspondence to physical materials but can also represent non-material influences (eg., topographic shadowing, textural effects, etc.).

An important goal of remote sensing studies is to untangle the mineralogic, lithologic, photometric, and other properties that contribute to the observed remotely 
sensed signal and to recast the scene in terms of mappable physical materials. However, remote sensing measurements at visible and near infrared (VNIR) wavelengths only probe the uppermost few microns of a planetary surface and thus may be dominated by the spectral signatures of fine-grained dust or soil coverings or coatings. Viewing geometry and lighting effects (including diffuse atmospheric illumination) also affect the observed spectra. These effects, that have the potential to affect analyses of VNIR measurements, are discussed in more detail below.

In the case of the Spirit rover and its exploration of the floor of Gusev crater, the initial color properties of the Gusev plains as measured by Spirit's Pancam exhibited a relatively low level of spectral variability. Major surface components of the Gusev plains were identified as basalts with varying amounts of dust/alteration coatings, bright soils, and dark soils [McSween et al., 2004, 2005; Bell et al., 2004a, 2005a]. In contrast, when Spirit reached the Columbia Hills, it encountered rocks with elemental compositions that were similar to basalt [e.g., Arvidson et al., 2005] but which, based on Rock Abrasion Tool (RAT) grinding energy, were much softer [Bartlett et al., 2005] and which, upon examination by the rover's Microscopic Imager (MI), were shown in some instances to be composed of cemented clasts [Rice et al., 2005]. In a broad sense, even in the Columbia Hills, many scenes measured by Pancam showed a broadly similar mix of dark rocks (again, with varying amounts of coating) and bright and dark soils [e.g., Bell et al., 2005a; Johnson et al., 2005]. However, in detail, the rocks (with minimum levels of coating) displayed a greater level of spectral heterogeneity than did the plains basalts. Some images also revealed examples of both the clastic hills rocks and plains basalts. 
Thus, Pancam image sequences collected in the Columbia Hills tended to have a higher level of spectral variability than did those gathered from the plains.

A methodology for determining the identity of spectral endmembers within a multispectral scene, and thus for assessing the spectral variability of the scene, is linear spectral mixture analysis (SMA). SMA is based on the assumption that each image in a multi- or hyperspectral scene can be modeled, within acceptable error limits, as a linear combination of the defined endmember spectra. SMA has been applied to telescopic [Singer and McCord, 1979] and lander based [Adams et al., 1986; Bell et al., 2002] VNIR data of Mars. At the broad telescopic scale considered by Singer and McCord [1979], the martian surface can be modeled as a two component, bright and dark, mixture. In examining multispectral data of the surface from the Viking [Adams et al., 1986] and Pathfinder [Farrand et al., 2001; Bell et al., 2002] landers, those scenes could be modeled as three to four endmember mixtures. In applying SMA to data from Spirit's Pancam, spectral endmembers can be identified and these endmember materials can be compared against measurements by other instruments in Spirit's Athena science payload [Squyres et al., 2003]. The availability of instruments on the rover's arm, or instrument deployment device (IDD), for in situ studies has enabled a more detailed examination of the nature of many of the materials observed by Pancam that have unique spectral signatures. The application of SMA provides a methodology for determining the best examples of the most spectrally unique materials observed at each site, including a means of identifying rock surfaces that have the least amount of dust coatings. Through the use of SMA, extracted rock endmember spectra are examined with confidence that dust coatings do not significantly contribute to the measured spectra. Also, by considering the 
VNIR reflectance of the eleven unique 400 to $1000 \mathrm{~nm}$ color channels gathered by Pancam, additional constraints are provided on the types of minerals that might be present.

In this paper, we first describe the methodologies of SMA and related techniques, including endmember detection techniques as they have been implemented in the analysis of MER/Pancam data. We then provide a discussion of the level of spectral variability observed at representative sites in Spirit's traverse from its landing site and into the Columbia Hills. Then, extracted rock endmember spectra from representative locations are compared in terms of selected diagnostic spectral parameters. Finally, the significance of these endmember materials, as well as that of some small scale anomalous materials which are also present in some scenes, is discussed in the context of the measurement of other physical, compositional, and mineralogic properties of these materials as measured by other Athena science instruments. The primary focus of this paper is on Pancam observations of rocks. A discussion of the VNIR spectral character of soils is provided by Bell et al. [2005a], and linkages between the VNIR and thermal infrared (as measured by Spirit's Mini-TES instrument) spectral characteristics of rocks examined by Spirit is provided by Blaney et al. [2005].

\section{Data}

A detailed description of the Pancam instrument is available in Bell et al. [2003] and further details on calibration throughout the mission are provided in Bell et al. [2005b]. In brief, the Pancam has two 1024 by 1024 active-area charge-coupled devices (CCDs) with a $30 \mathrm{~cm}$ stereo separation and a $0.27 \mathrm{mrad}$ per pixel resolution. The Pancam 
is mounted $1.5 \mathrm{~m}$ above the ground on a mast (the Pancam mast assembly or PMA). Each camera has an eight position filter wheel. One filter position on the left Pancam (the L1 band) is a broad band unfiltered channel. There are also two neutral density filters (the L8 and R8 bands) for solar observations. Of the remaining 13 filters for multispectral geologic investigations, two pairs of filters are common between both cameras, leaving 11 unique wavelengths. Table 1 lists the left and right eye band names, centers, and FWHM values of the 13 "geology" bands.

Over the course of the MER mission, "full spectral coverage" by the Pancam typically consisted of 13-filter observations using the channels listed in Table 1; these are the data sets used for the analyses reported on in this paper. Multispectral data from the Pancam left eye and right eye cameras were analyzed separately. Spectra that are presented are combined from both eyes with pixels manually selected from common areas. The goal was to equalize spectra using the L2 and R2 channels (respectively centered at 753 and $754 \mathrm{~nm}$ ). Custom software developed by the MER/Pancam team to analyze Pancam data can display spectra from both eyes simultaneously, allowing pixel spectra to be selected that match near $754 \mathrm{~nm}$. Overlap between $432 \mathrm{~nm}$ and $436 \mathrm{~nm}$ was sufficiently consistent that for clarity we show only the $432 \mathrm{~nm}$ data from the left eye camera; the right eye $436 \mathrm{~nm}$ filter data points are not shown.

Each Pancam was calibrated before launch as described in Bell et al. [2003; 2005b]. With the acquisition of multispectral image sets, a calibration target is also imaged. The calibration target (described in Bell et al. [2003; 2005b]) has multiple gray levels and a post that casts a shadow allowing for estimation of diffuse illumination. Multispectral image data from the calibration target, in conjunction with pre-launch 
calibration information, are utilized to convert raw image data to calibrated radiance and then to radiance factor $(\mathrm{I} / \mathrm{F}$, where $\mathrm{I}$ is the measured radiance and $\pi \mathrm{F}$ is the incident solar irradiance). Accumulation of airfall dust on the calibration target over the course of the mission led to development of a correction for dust on the calibration target based on a two-layer Hapke model along with the known photometric properties of the calibration target [Bell et al., 2005b, Sohl-Dickstein et al., 2005]. The solar incidence angle is recorded for each scene and image analysis software is used to convert the data to relative reflectance $\left(\mathrm{R}^{*}\right)$ [where $\mathrm{R}^{*}$ is defined as $\mathrm{I} / \mathrm{F}$ divided by the cosine of the incidence angle [Reid et al., 1999; Bell et al., 2005b]. Pancam spectra and spectral parameters that are presented here are from data converted to $\mathrm{R}^{*}$. Bell et al. [2005b] have estimated the absolute reflectance levels of these data to be accurate to within $\sim 10 \%$ at the shortest wavelengths, and probably slightly more accurate at longer wavelengths. Relative filterto-filter uncertainties in $\mathrm{R}^{*}$ are estimated to be smaller, typically $1-5 \%$, providing confidence in the reality of even very small-scale spectral variations detected in the scene. Data transmitted to Earth are first subjected to a wavelet-based compression. The 13-filter data sets examined here were typically compressed so that blue stereo bands (the L7 and R1 bands) were at 2 bits-per-pixel and all other bands were at 1 bit-per-pixel. Some of the scenes considered here had lower compression levels. Effects on the radiometric precision due to the compression were estimated to be $<1 \%$ based on prelaunch tests [Bell et al., 2005b].

As reported by Johnson et al. [2005] "Photometry QUBs" with incidence, emission, and phase angle data derived from Pancam stereo imagery have been computed for a subset of the available Pancam scenes. Incidence angle images from these 
photometry QUBs can be used to produce an adjusted version of $\mathrm{R}^{*}$, referred to here and by Johnson et al., [2005] as $\mathrm{R}^{*}{ }_{\mathrm{i}} . \mathrm{R}^{*_{\mathrm{i}}}$ is calculated by dividing the $\mathrm{I} / \mathrm{F}$ value for each pixel by the cosine of the calculated local incidence angle for that pixel (as opposed to the calculation of $\mathrm{R}^{*}$ where a single incidence angle appropriate for a flat planar surface is used over the entire scene). However, incomplete left/right eye disparity solutions sometimes lead to gaps in the stereo models near areas of interest in the regions studied here [cf., Alexander et al., 2005]. Examination of values of $\mathrm{R}^{*}$ and $\mathrm{R}^{*}$, and associated standard deviations indicate that $\mathrm{R}^{*}-\mathrm{R}^{*}{ }_{\mathrm{i}}$ pairs have overlapping standard deviation envelopes. It is our assessment that the effects of scatter due to viewing geometry differences with $\mathrm{R}^{*}$ data does not significantly alter the conclusions presented here regarding the identification of multiple lithologies in Gusev crater. Therefore, the work described here was performed with the $\mathrm{R}^{*}$ data and the recognition that local slope effects can cause some scatter in the absolute level of reflectance. We acknowledge that quantifying the significance of local topographic facets is the subject of important future work [e.g., Johnson et al., 2005].

\section{Methodology}

The basis of SMA and related techniques is the derivation of the endmembers for each scene. In the work described here, the spectral endmembers used were "image endmembers". An image endmember is a spectrum that is a single pixel spectrum or, more typically, an average of multiple pixel spectra that are defined as the best spectral representations of the endmember material within the data set. An alternative approach 
to SMA, commonly used with thermal infrared data, utilizes endmember spectra drawn from laboratory measured mineral spectra [Ramsey and Christensen, 1998].

A standardized methodology for the determination of image endmembers was developed by Boardman and Kruse [1994] and is incorporated in the commercial ENVI software [RSI, 2004]. In this methodology, the multispectral data set is first subjected to a Minimum Noise Fraction (MNF) transformation [Green et al., 1988]. The MNF consists of two cascaded Principal Components transformations and is intended to order the resulting MNF bands in order of increasing noise (instead of decreasing variance as is the norm for standard Principal Components Analysis). Eigenvalues are calculated during the MNF transformation, and they can be used as a measure of the spectral variability of the scene.

Examination of the MNF bands also provides insight into the level of spectral variability within the scene. A scene with a set of MNF bands that have discernable, spatially coherent patterns into the fourth or fifth MNF band is likely to have a higher level of intrinsic spectral variability than a scene showing variations in only the first few MNF bands. An example is provided in Figure 1. Fig. 1a shows the first four MNF bands for a left eye scene from sol 297, image sequence P2546 of the rock "Lutefisk." In this example, there are coherent patterns in the third MNF band, but the fourth MNF band is dominated by noise. This is an example of a scene with a low level of spectral variability. Fig. $1 \mathrm{~b}$ shows the first six MNF bands for a right eye scene from sol 87 , image sequence P2530 for the RAT-abraded (henceforth in this paper, rocks ground into by the RAT will be referred to as having been "RATted") rock "Mazatzal". In this case there is persistence of spatially coherent regions into the fifth MNF band. 
A principal reason for performing the MNF transformation is to compress the relevant signal from the multispectral scene into a smaller number of bands. All the image pixels from this smaller number of bands can be examined in two dimensional scattergrams (e.g., MNF 1 vs. MNF 2), RGB color composites, or using an interactive ndimensional visualization tool such as is resident in the commercial ENVI software [RSI, 2004]. The shape of the resulting data cloud is indicative of the level of spectral variability, also known as the "intrinsic dimensionality" of the scene. A scene that can be modeled using three endmembers can be captured in a two dimensional space and thus has an intrinsic dimensionality of two. A scene that requires four endmembers defines a three dimensional space and has an intrinsic dimensionality of three. The same sol 297 P2546 scene referenced above has an intrinsic dimensionality of two and a resulting triangular shaped data cloud that is shown in Figure 2. The data cloud shown in Figure 2, and those in examples to follow, are shown without axes. This is done because these are two dimensional "snapshots" of a rotating three dimensional data cloud and, as such, any axes would be somewhat arbitrary. The important parameter is the shape of the data cloud and the presence (or absence) of vertices or knobs on the data cloud.

It is apparent that the data cloud in Figure 2 has curved boundaries. This is evidence that mixing in the system is not strictly linear. Non-linear mixing can occur, for example, when photons interact with multiple materials before being scattered back towards the sensor, or when highly opaque or pigmentary grains are present within the materials. An example from terrestrial remote sensing is leafy canopies [Ray and Murray, 1996], which involve multiple scattering interactions between both minerals and vegetation for incident and emitted light. In the case of remote sensing of the surface of 
Mars, a prominent situation leading to non-linear mixing is that where there are optically thin dust coatings on rocks. As discussed in Bell et al. [2002] and as demonstrated below, such optically thin dust coatings have been observed to produce areas not well modeled by the other endmembers; e.g., they appear as areas with high residual error (measured as the root mean square of the residuals--RMS error) values.

Image endmembers can be interactively selected from the $\mathrm{n}$-dimensional data cloud. In the case of the example shown in Figure 2, the image endmembers are averages of those pixels that define the vertices of the triangular shaped data cloud. In instances where there is a material that is represented in the scene by a relatively small number of pixels, those pixels might be manifested on the data cloud as a bump or spur on the boundary of the data cloud.

Having determined a set of initial image endmembers, these endmembers can be used to model the data through SMA. The basic equation for SMA, in vector form, is:

$$
r(x, y)=\alpha \mathbf{M}+n
$$

where: $r(x, y)=$ the relative reflectance spectrum for the pixel at position $(\mathrm{x}, \mathrm{y}), \alpha=$ the vector of endmember abundances, $\mathbf{M}=$ the matrix of endmember spectra, and $n=$ the vector of residuals between the modeled and the measured relative reflectances. The output from SMA is a set of fraction images, one for each endmember, and an RMS error image. Examples are provided in the following section. In the fraction image for a given endmember, the data number (DN) of each pixel represents the relative abundance of that material in the pixel, or, more accurately, it represents how much the spectrum of that endmember contributes to the modeled spectrum of that pixel. The data numbers of pixels in fraction images ideally range between zero and one. However, in practice there 
can be some overflow to values outside this range. Excessive numbers of pixels with values less than zero or greater than one in a fraction image is an indication that the image endmember associated with that fraction image was not an optimum endmember.

SMA generates an RMS error image that is calculated according to the following equation:

$$
\varepsilon=\left[\mathrm{M}^{-1} \sum_{\mathrm{c}=1}^{\mathrm{M}} n_{\mathrm{c}}^{2}\right]^{1 / 2}
$$

where $\varepsilon=$ the RMS error, $\mathrm{M}=$ the number of channels, $\mathrm{c}=$ channel number, and $n=$ the vector of residuals between the modeled and the measured relative reflectances. The RMS error image provides an indication of how well the chosen endmembers model the spectral variability of the scene and whether there are additional endmembers present which are not well modeled by the initially chosen ones. These additional endmembers must have reflectance spectra that are distinct in some way from the initially chosen endmember spectra because they are manifested in the RMS error image as spatially coherent regions with high RMS error. The values of RMS error that are deemed as "high" will vary from scene-to-scene.

The implementation of SMA used in this study is based on the algorithm described by Adams et al. [1993] and Smith et al. [1990]. It incorporates the methodology described above, but differs from the linear spectral unmixing program incorporated into commercial packages such as ENVI in the way it handles the so-called "shade" endmember. "Shade", as used in this implementation of SMA, is not a physical material but rather represents the "dark point" in the image scene; i.e., an ideal shade endmember would be a shadowed surface with zero reflectance at all wavelengths. In 
practice, the shade endmember consists of pixel averages from the darkest shaded regions. As used in this study, the shade image endmember was first subtracted from the material endmember (generally "rock" and "bright material") spectra. SMA was then run using only the non-shade material endmembers. The shade fraction image was then calculated by subtracting the sum of the material endmember fraction images from 1.0. We note that the shade endmember certainly includes a diffuse red (and nonlinear) "skylight" component [e.g., Thomas et al., 1999; Lemmon et al., 2004, Johnson et al., 2005] and that by subtracting it from the spectra of the material endmembers a simple diffuse illumination correction is performed. While subtracting shade from the material endmember spectra does not rigorously remove the diffuse illumination component from the scene, it does allow us to make estimates of material endmember fractions that are much less influenced by sky illumination. Further discussion of the consequences of not using a shade endmember or use of inappropriate shade endmembers in terrestrial remote sensing examples is provided in Farrand [2001].

Anomalous materials identified in RMS error images might only constitute a spatially small region in the scene, for example just a single cobble or patch of soil. In such an instance, the spectrum for the anomalous material might not be appropriate to add to the set of image endmembers since it would not substantially contribute to the modeling of the larger set of pixels across the scene. In order to map out these low abundance materials, an alternative method for mapping the fractional abundance of materials was used, namely the constrained energy minimization (CEM) technique [Harsanyi, 1993; Farrand and Harsanyi, 1997] which is implemented in the ENVI software package under the name "matched filter". The CEM method is based on the 
linearly constrained adaptive beam-forming problem from the signal processing community. The solution to this problem is to minimize the average power received by a multi-element antenna array subject to the constraint that a constant, unity response in the presumed direction of the target signal is maintained. In the instance of CEM, a vector operator $\boldsymbol{w}$ is determined that suppresses the unknown and undesired background spectra while enhancing that of the known target spectrum, $\boldsymbol{d}$. The operator, $\boldsymbol{w}$, is defined by constraints to minimize the total output energy of all pixels and to require that when the operator is applied to the target signature, the output is 1.0. A solution that meets these constraints is provided by:

$$
w=\frac{\mathbf{R}_{\mathrm{r}}^{-1} d}{d^{\mathrm{T}} \mathbf{R}_{\mathrm{r}}^{-1} d}
$$

where: $\mathbf{R}_{\mathrm{r}}^{-1}=$ the inverse of the sample correlation matrix of the multispectral scene. Since $\mathbf{R}$ is ill-conditioned for multispectral images, it is difficult to calculate $\mathbf{R}^{-1}$. To circumvent this difficulty, the sample correlation matrix can be approximated by:

$$
\mathbf{R}=\mathbf{V} \boldsymbol{\Lambda} \mathbf{V}^{\mathrm{T}}
$$

where: $\mathbf{V}$ is a matrix populated by the eigenvectors of the sample correlation matrix, and $\Lambda$ is a diagonal matrix with the eigenvalues of the sample correlation matrix. $\mathbf{V}$ can be approximated by a smaller matrix populated just with the first $p$ significant eigenvectors. The "matched filter" implementation of CEM contained in ENVI was used in this study. The image pixels determined through the endmember identification approach outlined above or through identification as high RMS error region(s) in RMS error images are considered the most spectrally "pure" examples of the materials responsible 
for the observed spectra. Since this paper focuses on the analysis of rocks, the rock endmembers obtained should be the most dust/coating free regions in each scene. Thus, these are the best image spectra to work with in terms of characterizing the VNIR spectral properties of the rocks examined over the course of Spirit's exploration of Gusev crater.

Another processing approach used in the analysis of Spirit's Pancam data was the decorrelation stretch technique [Gillespie et al., 1986]. The use of the decorrelation stretch was also used to good effect in the analysis of color images collected at Meridiani Planum by the Opportunity rover [Farrand et al., 2005a,b]. Color differences that are subtle in simple three color composites are exagerated through the use of the decorrelation stretch. The decorrelation stretch consists of a principle components (PC) transformation of three selected image bands. The PC transformed bands, are contrast stretched and then transformed back into the original image space.

VNIR spectral properties can be categorized in terms of a set of spectral parameters. The Pancam VNIR spectral parameters considered in this study are listed in Table 2. This set of spectral parameters is similar to the set of parameters developed for multispectral analysis of Mars Pathfinder (MPF) data [Bell et al., 2000], and was selected after examining a number of rock endmember spectra. Parameters such as the $535 \mathrm{~nm}$ band depth and the visible slope from 535 to $601 \mathrm{~nm}$ are related to the degree of oxidation or amount of dust contamination of the rock. As noted above, the SMA methodology is effective at finding the rock surfaces that are least influenced by dust, but this does not mean that there is no contamination from dust. However, comparison of these Pancam left eye parameters (the shortest wavelengths are those most likely to be 
influenced by the stronger $\mathrm{Fe}^{3+}$ - related absorptions in the martian bright dust) from ostensibly "clean" natural rock surfaces against RAT-brushed surfaces indicate comparable parameter values, thus providing confidence in the approach. An example can be provided by examining the $535 \mathrm{~nm}$ band depth and 535 to $601 \mathrm{~nm}$ slope of a brushed surface on the rock "Ebenezer" and an undisturbed surface (determined by SMA to be a "clean" rock surface) on an adjacent rock from the sol 238 P2585 image sequence. Table 3 shows values of these parameters for these surfaces. For context, the minimum and maximum values of these parameters for this scene (along with the standard deviation over the scene) are provided as are the values for the "bright dust" image endmember. Given the range in values for these parameters, the match between the brushed and undisturbed surface is good. Further examples with "bare" rock surfaces being well modeled by SMA with spectra from brushed surfaces are presented below.

The near-infrared (NIR) parameters proved most valuable in distinguishing rock spectral classes observed in Gusev crater. The $900 \mathrm{~nm}$ band depth can be interpreted as a measure of the relative abundance of $\mathrm{Fe}^{3+}$ and/or $\mathrm{Fe}^{2+}$ - bearing minerals with an absorption at or near $900 \mathrm{~nm}$. Likewise, the $800 \mathrm{~nm} / 900 \mathrm{~nm}$ ratio is another measure of the relative strength of such an absorption feature. The NIR slope from 754 to $864 \mathrm{~nm}$ provides information on both the relative reflectance maximum between the long wavelength absorption and the UV-Vis absorption edge and on the position of the long wavelength absorption. For example, a material with a strong absorption centered at 900 nm will have a steeper (more negative) NIR slope than a material with a weak absorption centered at $1000 \mathrm{~nm}$. The NIR slope from 754 to $1009 \mathrm{~nm}$ provides an indication of the slope at wavelengths longer than $1009 \mathrm{~nm}$; i.e., a positive 754 to $1009 \mathrm{~nm}$ slope indicates 
a NIR "red" spectrum (increasing values at longer wavelengths). A negative 754 to 1009 nm slope indicates a NIR "blue" spectrum (decreasing values with increasing wavelength).

\section{Spectral mixture analysis of sites in Gusev Crater}

To date, Spirit has examined the plains of Gusev crater, the base of the Columbia Hills (the lower West Spur), the West Spur of Husband Hill, the northwestern flank of Husband Hill, and the "Cumberland Ridge" portion of Husband Hill that includes the rock outcrops at Larry's Lookout, Jib Sheet, and Methuselah [Arvidson et al., 2005]. This paper deals with observations collected through sol 419 of Spirit's mission before the rover examined the Jib Sheet and Methuselah outcrops. SMA applied to Pancam 13filter scenes gathered from these locations has revealed similarities and differences between these locations. Salient observations derived from SMA of these scenes are divided in the following discussion into sections describing low spectral variability natural/undisturbed scenes, higher spectral variability natural/undisturbed scenes, and scenes where rocks have been ground into or brushed by Spirit's Rock Abrasion Tool (RAT). The action of driving over the surface also disturbs the natural surface and such disturbed soils can potentially be used as additional endmember(s) in SMA; however, consideration of such scenes is the focus of other detailed studies [Knudson et al., 2005; Wang et al., 2005].

\subsection{SMA of Low Spectral Variability Undisturbed Scenes}

Spectral variability on the Gusev plains tends to be relatively low. Most Pancam scenes can be well modeled, in both left and right eye image sequences, using only three 
endmembers: shade, bright dust/coatings, and rock. On the Gusev plains the brightest material in the scene, which was used as an endmember in SMA, could be selected from bright drift deposits or from bright rock coatings, although the bright rock coatings were most often used as the "bright" image endmember. This represents a difference from what was observed at the MPF site where there was a smaller percentage of coated rocks and bright drift was most often used as the "bright" endmember [e.g., Bell et al., 2002]. While most left and right eye scenes on the Gusev plains could be well modeled by a single "bright" endmember, some required a fourth endmember so that both bright materials, drifts and coatings were separately represented. An example of the potential for adding an extra "bright" endmember is show in Figure 3. Figure 3a shows a single band image of the sol 76 P2567 image sequence centered on the rock Mazatzal. Figures 3b-e are the fraction and RMS error images derived from a three endmember SMA of the left eye data of that scene (endmembers were derived from a shaded region, from relatively clean rock surfaces and from bright drift). In the RMS error image in Figure $3 \mathrm{e}$, it can be seen that there are spatially coherent bright patches associated with portions of rock surfaces that appear to have thin rock coatings. Analysis of color composites indicates that these regions have color properties intermediate between rock and dust/thick coatings. Pixel averages of these bright, thin coating regions could potentially be used as an additional endmember. This observation that some thinly coated areas are not well modeled in three endmember mixtures was also observed in SMA of MPF data [Bell et al., 2002]. Those authors made the observation that the poor fit for these regions was likely a case of non-linear mixing between the thin coatings and the rock surface. 
On approximately sol 156 of Spirit's mission, the rover crossed a regional geologic contact, crossing from the Hesperian aged basalt-dominated plains to the Noachian aged terrain dominated by the materials making up the Columbia Hills [Crumpler et al., 2005]. The macroscopic scale texture of surface materials, visible even in the rover's Navigation camera (Navcam) images, changed after crossing the contact. While the rocks littering the Gusev plains are basalts, the rocks making up the Columbia Hills are chemically similar to basalts, but are clastic in nature [Arvidson et al., 2005; Squyres et al., 2005, Rice et al, 2005] and some have been altered by aqueous processes [Ming et al., 2005]. As noted in the following section, many Pancam 13 filter scenes showed variability in the spectral character of Columbia Hills rocks; however, many scenes were as simple, in terms of spectral variability, as scenes collected on the Gusev

plains. In fact, the example of a simple three endmember scene provided in Figures 1 and 2 is a scene collected from the West Spur of Husband Hill.

\subsection{SMA of Higher Spectral Variability Undisturbed Scenes}

SMA of Gusev plains Pancam 13 filter scenes examined in this study did not indicate any significant spectral differences among nominally bare rock surfaces on the plains; this was not the case in the Columbia Hills terrains. The first set of rocks examined at the base of the Columbia Hills, in the region dubbed "Hank's Hollow" in honor of the late USGS geologist Hank Moore, displayed different spectral characteristics from the plains rocks. Some isolated examples of plains basalts were also present in at least one of these scenes. Some of the rocks within Hank's Hollow exhibited cavernous weathering textures [Arvidson et al., 2005; Rice et al., 2005]. The rover performed in situ examinations of a rock called "Pot of Gold" with an especially unusual knobby texture. 
A number of 13-filter observations were also made of Pot of Gold and surrounding rocks exhibiting the characteristic cavernous weathering patterns. Figure 4a shows a R5, 2, 1 $(904,754,436 \mathrm{~nm})$ composite of a subsection of the sol 159 P2597 image sequence centered on Pot of Gold. The plot of the data cloud of pixels from the first three MNF bands (Figure 4b) shows at least 5, possibly 6, spurs (contrast this figure with the simple triangular data cloud in Figure 2). As the spectra in Figure 4c show, an average pixel spectrum from one of the knobs on Pot of Gold has a distinct $900 \mathrm{~nm}$ absorption while the rock in the upper right portion of the right eye P2597 scene has a spectrum more consistent with "normal" Gusev plains basalt. This example demonstrates the ability of Pancam data to distinguish between different rock types based on their VNIR reflectance spectra.

As Spirit proceeded up onto the West Spur of Husband Hill it encountered apparent bedrock outcrops and out of place rocks which, on first glance, resembled Gusev plains basalts in that they were dark with various levels of coating. In situ examinations with the rover's Microscopic Imager (MI) and other instruments indicated that these rocks are very different from plains basalt, although their major-element chemistry (as measured by Spirit's APXS) remains, overall, basaltic albeit with some rocks showing significant enrichment or depletion in key elements [Ming et al., 2005]. Examination of Pancam multispectral images in this region indicates that there is more variability among the spectra of these rocks than was observed among rock spectra on the Gusev crater plains. An example is provided in Figure 5 which shows data from sol 195 looking at the rock target "Viera Cairns" near the rock "Wooly Patch," which was examined in situ [Wang et al., 2005]. In Figure 5a it can be seen that there is a distinct 
spur on the data cloud representation of the first three MNF bands from right eye data of the sol 195 P2548 scene. In Figure 5b the areas that correspond to the pixels circled in Fig. 5a are shown superimposed on a single band image of this scene. Pixels from the main "rock vertex" of the n-dimensional data cloud translate to pixels on the large rocks in the foreground of the scene and also in the far field. Pixels from the spur correspond to rocks in between this set of "main rocks". Figure 5c shows a composite of CEM fraction images (each stretched between 0 and 1) with green assigned to rocks from the main "rock vertex" and red is assigned to the spectral class corresponding to the spur. The difference in their VNIR spectra suggests that the band of rocks colored in red in Fig. $5 \mathrm{c}$ could be composed of a somewhat different material than those colored in green. Combined-eye R* spectra of the two rock spectral classes are shown in Figure 5d. The main differences between these spectra are in the depth of the absorption feature centered near 900 to $934 \mathrm{~nm}$ with the "red" rocks having a deeper more well-defined $900 \mathrm{~nm}$ band. Further discussion on the significance of the differences in Columbia Hills rocks VNIR spectra is provided below.

Further up on the West Spur, other scenes collected in the "dark rocks" region near the rocks "Clovis" and "Ebenezer" that were subjected to in situ examination also showed the presence of different spectral rock classes. Figure 6 shows representative spectra. The spectra differ in that the main rock spectral class, represented in this figure from spectra extracted from the rock "Pico", has a shallower NIR slope (from 754 to 864 $\mathrm{nm}$ ) and a shallower long wavelength band depth. Also, Pico has a reflectance maximum at $673 \mathrm{~nm}$ and the "rock 2" class, represented in the scene examined by smaller, unnamed 
rocks, has a reflectance maximum at $803 \mathrm{~nm}$, a deeper $900 \mathrm{~nm}$ band depth, and a positive slope from 803 to $1009 \mathrm{~nm}$.

In these examples, the differences in the VNIR rock spectra were not noted until long after the rover had moved from the area, and so supporting information from other instruments is not available. A scene with two distinct rock types that has been verified by thermal infrared spectroscopy with Mini-TES [Ruff et al., 2005] is the sol 343 P2543 image sequence collected on the flank of Husband Hill. In the foreground of Figure 7a is the rock "Maids Milking," whose thermal emission spectrum most closely resembles a plains basalt. Other rocks in the scene have spectra similar to those observed on the rock "Wishstone", which was examined in situ circa sol 380. The n-dimensional data cloud resulting from plotting the first several MNF bands from this scene shows a distinct spur that corresponds to pixels on the rock Maids Milking while the main rock vertex consists of pixels that relate back to Wishstone-class rocks in the scene. A circle, square and triangle are superimposed on rocks in the single band image in Figure 7a. These correspond to spectra in Figure 7b where it can be seen that the Maids Milking basalt has a longer NIR band center than the Wishstone-class rocks. The small rock in the scene has a Pancam spectrum that is also consistent with basalt based on its longer NIR band center.

\subsection{SMA of Scenes of Rocks Abraded by the RAT}

The action of applying the rover's Rock Abrasion Tool (RAT) to rock surfaces altered the apparent composition of scenes to the extent that a fourth or even fifth endmember are required in SMA conducted on these scenes. An example is given in Figure 8 from image sequence P2530 on sol 87, viewing the RAT abraded (both brushed 
and ground) surfaces of the rock "Mazatzal." Four fraction images representing shade, bright material, natural rock and RAT cuttings are shown along with the RMS error image for the scene (Fig. 8e). The RMS error image shows coherent high RMS error regions which could be used either as other endmembers or as targets for mapping via CEM.

Examination of the 13 filter Pancam data of Columbia Hills rocks that were ground into or brushed by the rover's RAT sometimes indicated color differences between RAT-ground and RAT-brushed surfaces. Figure 9a shows a Pancam band L3, 5, and $7(673,535$, and $432 \mathrm{~nm})$ decorrelation-stretch composite of the RAT-ground and RAT-brushed rock "Clovis." Even from this simple color composite it can be seen that the brushed areas have spectral properties distinct from those of the RAT-hole interior which are manifested in the decorrelation stretch image as a cyan color for the former and a purple color for the latter. In fact, examination of MI images of the RAT-hole interior show a high fraction of particulate matter (e.g., RAT cuttings) in the RAT-hole interior. SMA provides an effective means of determining the relative abundance of spectrally significant materials over a given area. From the decorrelation stretch image in Figure 9a, a group of the most cyan colored pixels (most like the brushed area) were selected in the RAT hole. After performing a four endmember (shade, bright materials, RAT cuttings, brushed rock) SMA on the left eye data of the sol 226 P2569 scene, it was found that even these pixels displayed a modeled fractional abundance of $74 \%$ RAT cuttings (although as noted above, these fractions must be considered in a relative sense due to the potential for non-linear mixing). Figure $9 \mathrm{~b}$ shows the spectra of the RAT cuttings and the brushed rock (brushed-rock spectrum offset upwards by 0.02 ). The RAT cuttings have a 
steeper VNIR slope and the location of that absorption edge is offset to a longer wavelength; both features appear to be consistent with higher oxidation in the cuttings than on the brushed rock surface.

An exception where the RAT hole had similar spectral properties to naturally "clean" surfaces, and a high similarity to the RAT cuttings is the previously referenced example of the rock "Ebenezer." Examination of the MI images of the Ebenezer RAT hole showed that it was a "cleaner" hole with fewer RAT cuttings. A spectrum of the RAT-hole cuttings indicated, as with Clovis, a steeper VNIR slope in the cuttings compared to the clean rock surface. SMA modeling of the left- and right-eye data showed that the RAT-hole interior endmember also modeled the RAT cuttings well, indicating a greater degree of spectral similarity between the rock surface and the RAT cuttings than in the case of Clovis. In other words, after using the RAT-hole interior as the "rock" endmember in a three endmember mixture model, the blanket of RAT cuttings did not have high RMS error values. Also, in SMA of both the left and right eye data, the fraction image for the RAT-hole-interior endmember had high fractions for both the RAT-hole and dark naturally-clean-rock surfaces (Figure 10).

The rock "Uchben" also had a RAT-brush spot and a RAT hole ground into it and as with Ebenezer, the RAT hole in Uchben was relatively free of RAT cuttings. The RAT hole in Uchben also had several dark patches visible in the Pancam images. Examination of the MI mosaic of the RAT hole (Figure 11) reveals that the largest of these was actually a depression in the rock that was not planed away by the RAT's grinding action. A three endmember (shade, bright materials, and RAT-hole interior) SMA was performed on both the left and right eye image sequences of the sol 293 P2543 
scene covering the RATted Uchben. For both eyes, the brushed and RATted material were both well modeled by three endmembers. As in the other RAT holes, the cuttings had a higher blue to red slope and red/blue ratio, but, as shown in Figure 12, were otherwise similar in spectral shape to the RAT-hole interior. The brushed spot is similar to the RAT-hole interior in the left eye bands, but differs in the right eye bands in that it has the upturn in reflectance at the longest wavelength R7 (1009 nm) band. Interestingly, the incompletely RATted area in the RAT hole also has the same upturn in reflectance in the R7 band. This makes sense since this part of the RAT hole was, essentially, only brushed and thus it is reassuring that its spectrum is similar to the brushed area on Uchben. What remains unclear, and will be discussed to some extent below, is why the RAT-ground area has a different reflectance spectrum than the brushed area. Spectra of the RAT-ground area versus the RAT-brush area are shown in Figure 12.

\section{Discussion and Summary of VNIR Spectral Properties}

\subsection{Groupings of Gusev crater rocks based on spectral parameters}

The above results from scenes from the Gusev crater plains into the Columbia Hills illustrates the greater spectral variability of rocks exposed in the Columbia Hills as opposed to the plains. Examination of rocks by other instruments in Spirit's Athena science payload has confirmed chemical (via the APXS [Gellert et al., 2005]), iron mineralogy (via the Mössbauer spectrometer [Klingelhoefer et al., 2005]), and other mineralogic (via the Mini-TES [Ruff et al., 2005]) differences between rocks in locations on the Columbia Hills examined by Spirit. 
Examination of rock endmember spectra from the SMA analyses described above indicate approximately 6 groupings of rocks based on distinctive spectral parameters. These groupings largely correspond with units identified by Arvidson et al.[2005] and also referenced by other papers in this issue [eg., Squyres et al., 2005; Ming et al., 2005; Morris et al., 2005]. These groupings are: the plains basalts (typified by the rock "Adirondack"), rocks at the base of the West Spur of Husband Hill (the "Lower West Spur class"), rocks on the West Spur in the vicinity of the rock Clovis (the "Clovis class"), rocks on the lower northwest flank of Husband Hill (typified by the rock "Wishstone"- the "Wishstone class"), and rocks on the Cumberland Ridge portion of Husband Hill in the "Larry's Lookout" region, typified by the rock "Watchtower" - the "Watchtower class"). Measurements of the RAT-ground area on the rock "Peace" represent an additional distinct grouping (the "Peace class"). However, given that these are just two measurements from a single RAT hole, the Peace measurements are left out of some of the following discussion of inter-group comparisons, but are discussed in more detail below. We note that the Lower West Spur rocks are included in the Clovis class by Squyres et al. [2005]; however, we find that in terms of their VNIR spectral properties, Lower West Spur rocks are distinct from other rocks higher on the West Spur. Lower West Spur rocks exhibit some of the highest $900 \mathrm{~nm}$ band depths and highest 803 $\mathrm{nm} / 904 \mathrm{~nm}$ ratios seen for rocks at Gusev crater. While most closely related to the Clovis class, rocks such as Pot of Gold and Wooly Patch are chemically distinct from other Columbia Hills rocks [Ming et al., 2005; Wang et al., 2005] and Squyres et al [2005] acknowledge that the determination of their proper place in the emerging stratigraphy of the Columbia Hills is difficult. Therefore, we retain these rocks as a 
separate class in the ensuing discussions. In the spectral parameter plots presented below, Watchtower class rocks generally plot very closely with the Clovis class rocks, but still represent a distinct grouping. Representative spectra from each of these groupings are shown in Figure 13, characteristic spectral features of these groupings are summarized below and listed in Table 4.

There are several spectral characteristics in Table 4 that are deserving of additional discussion. The "band minimum column" refers to the expression of the ${ }^{6} \mathrm{~A}_{1}$ $\rightarrow{ }^{4} \mathrm{~T}_{1 \mathrm{~g}}$ feature [Sherman and Waite, 1985] that frequently occurs in Fe-bearing minerals at, or beyond, $900 \mathrm{~nm}$. The relative reflectance maximum occurs between this feature and the shorter wavelength crystal field and charge transfer absorptions in the UV to green wavelengths. This feature shows some variability even within groups. For example, Wishstone class rocks most often have a reflectance maximum at $754 \mathrm{~nm}$ but can have a flat maximum between the 673 and $754 \mathrm{~nm}$ bands. Spectra of undisturbed Watchtower class rocks have their reflectance maximum at $754 \mathrm{~nm}$, but that of the Watchtower outcrop RAT hole is at $803 \mathrm{~nm}$.

The division of the Gusev crater rock groups into six spectral classes is made on the basis of the groupings that become apparent in the spectral parameter plots of Figures 14 - 16. These figures show plots of mean values of spectral parameters defined in Table 2 for observations listed in Table 5. Group averages of the spectral parameters (averaged from the rocks listed in Table 5) are shown in Table 6. Several trends and groupings become apparent upon examination of these spectral parameter plots. In all the plots, the group with the tightest clustering is the Adirondack class basalts. All the Columbia Hills rock groups show more scatter, indicative of the higher level of spectral variability in the 
Hills and consistent with the SMA processed scenes discussed above. Some of the most significant trends are seen when the NIR ratio of R3/R5 (803 nm/904 nm) is compared against the NIR slope from the R2 to R4 bands or 754 to $864 \mathrm{~nm}$ (Figure 14) and against the NIR slope from the R2 to R7 bands or 754 to $1009 \mathrm{~nm}$ (Figure 15). In both, there is a clear linear trend from some of the Lower West Spur rocks to the Watchtower and Clovis class rocks. In the NIR ratio vs. 754 to $864 \mathrm{~nm}$ slope plot in Fig. 14 there is a trend from positive NIR slope and lower NIR ratio to a negative NIR slope and higher NIR ratio, with Adirondack class basalts and the measurements from the Peace RAT-hole defining the mid-point of this trend. In the plot of NIR ratio vs. the 754 to $1009 \mathrm{~nm}$ slope (Figure 15), Watchtower class rocks are distinct by having the only positive 754 to $1009 \mathrm{~nm}$ slopes. As was noted previously, several Lower West Spur rocks (Pot of Gold, Wooly Patch Mastodon and Wooly Patch scuffs) are also distinct with their high NIR ratios and very negative 754 to $1009 \mathrm{~nm}$ slopes.

In the $535 \mathrm{~nm}$ band depth vs. $900 \mathrm{~nm}$ band depth plot of Figure 16, plains basalts (and the two Peace measurements) are separate (with shallower to negative $535 \mathrm{~nm}$ band depths and generally low $900 \mathrm{~nm}$ band depths) from the general trend of the Clovis class through Wishstone class rocks. A dashed line is drawn on the plot at $535 \mathrm{~nm}$ band depth equal to 0.009 . Highly oxidized rocks from the Clovis, and Watchtower classes, and some Wishstone class rocks, have $535 \mathrm{~nm}$ band depths greater than 0.009 . Basalts, the Peace RAT-hole interior, Lower West Spur rocks (except for Viera Cairns), some Wishstone class rocks (the Wishstone RAT-hole interior, LaBrea, and an unnamed rock from the sol 381 P2543 scene that includes Peace) have $535 \mathrm{~nm}$ band depths less than 0.009 . 
$535 \mathrm{~nm}$ band depth can be used as a measure of the degree of oxidation and/or development of crystalline $\mathrm{Fe}^{3+}$ phases. Mössbauer spectrometer results indicate that Clovis class rocks from near the top of West Spur and Watchtower class rocks have a higher ratio of $\mathrm{Fe}^{3+} / \mathrm{Fe}_{\text {Total }}$ than the Wishstone and Peace class rocks [Ming et al., 2005] and the Wooly Patch outcrop at the base of the West Spur. Figure 17 shows a plot of $\mathrm{Fe}^{3+} / \mathrm{Fe}_{\mathrm{Total}}$ as measured by Spirit's Mössbauer spectrometer versus $535 \mathrm{~nm}$ band depth as measured by Pancam. With all points, the linear correlation coefficient for this plot is 0.719. Excluding the Wishstone RAT-hole, and the post-grind Clovis (which constitute the outlier points in Fig. 17), the linear correlation coefficient is 0.849 . Excluding those two points is reasonable since, as mentioned above, the Clovis RAT-hole was contaminated by RAT cuttings. Also, in the sol 381 observation of the Wishstone RAThole, the shortest wavelength bands in that image sequence were affected by saturated pixels in part of the RAT-hole. Pixels that did not appear to be affected were used in the calculation of $535 \mathrm{~nm}$ band depth, but the outlier status of the measurement in this plot could indicate that even the pixels that were used were affected by that saturation effect.

\section{$\underline{5.2 \text { Summary of spectral classes }}$}

\subsubsection{Adirondack Class Basalts}

The confident identification of rocks on the Gusev plains as picritic basalts [McSween et al., 2004; 2005] suggests an assemblage of clinopyroxenes and olivines in these rocks. The influence of olivine, with its broad $1000 \mathrm{~nm}$ absorption band likely helps to account for the relative reflectance maximum in these spectra generally occurring at $673 \mathrm{~nm}$. The fact that band minima for these rocks is observed most often in the $934 \mathrm{~nm}$ band indicates the influence of pyroxenes with a shorter band center. 


\subsubsection{Wishstone Class and Lower West Spur rocks}

Examination of the spectra in Figure 13 and the characteristics in Table 4 shows that the spectra of Wishstone Class and Lower West Spur rocks, to the first order, resemble the spectra of plains basalts. Both groupings have long wavelength band minima at $934 \mathrm{~nm}$, have reflectance maxima at 673 to $754 \mathrm{~nm}$ (though the plains basalts most often have a $673 \mathrm{~nm}$ reflectance maximum and the Wishstone class rocks most often have a $754 \mathrm{~nm}$ reflectance maximum), and have an intermediate to steeply negative NIR slope. Mössbauer and Mini-TES measurements indicate that these rocks contain many basaltic components: plagioclase and pyroxene with or without olivine- albeit in a clastic structure. The Pancam spectra are consistent with this basaltic mineral assemblage albeit perhaps with a stronger influence of pyroxene rather than olivine (causing the deeper long wavelength absorption band). This assessment is borne out by

Mössbauer evidence that shows that the Lower West Spur (Pot of Gold and Wooly Patch) and Wishstone classes of rocks have abundant (on the order of 30\%) pyroxene and have a higher pyroxene/olivine ratio than do the Adirondack class basalts [Morris et al., 2005].

\subsubsection{Clovis Class rocks}

The Clovis class rocks, best exemplified by the example spectra in Figure 13, have a relative reflectance maximum at $673 \mathrm{~nm}$. The ${ }^{6} \mathrm{~A}_{1} \rightarrow{ }^{4} \mathrm{~T}_{1 \mathrm{~g}}$ band minimum is sometimes seen at $934 \mathrm{~nm}$ (as in the sol 220 Pico spectrum in Fig. 13d) but West Spur rocks also display negative slopes through the final R7 (1009 nm) band (as in the Fig. $13 \mathrm{~d}$ sol 227 Frio spectrum) indicating either no well defined ${ }^{6} \mathrm{~A}_{1} \rightarrow{ }^{4} \mathrm{~T}_{1 \mathrm{~g}}$ feature or one whose minimum occurs at, or longer than, $1009 \mathrm{~nm}$. Further discussion of the possible nature of the Clovis class rocks is provided below. 


\subsubsection{Watchtower class rocks}

The spectra of the Watchtower class rocks are distinctive in that they display a shorter wavelength $(900 \mathrm{~nm})$ for the long wavelength absorption band minimum and some have a positive near-infrared slope between the reflectance maximum (most often at $754 \mathrm{~nm})$ and the R7 (1009 $\mathrm{nm})$ band. Mössbauer spectra indicate that these rocks are highly oxidized and contain hematite, goethite, and nanophase $\mathrm{Fe}^{3+}$ oxides [Morris et al., 2005]. Hematite spectra, convolved to Pancam bandpasses, also have a reflectance maximum at $754 \mathrm{~nm}$ and a positive near-infrared slope. Further discussion aimed at reconciling the Mössbauer results and Pancam spectra is provided in section 5.3.2.

\subsubsection{Peace Class}

A unique set of spectra were obtained from the 13-filter observation of the RATground area on the rock Peace. Two representative spectra of pixel averages from within the Peace RAT hole are shown in Figure 18a and the locations from which these pixel averages were extracted are indicated in Fig. 18b. As was mentioned above, these measurements from within the Peace RAT hole had among the lowest $535 \mathrm{~nm}$ band depth values measured of any natural or RAT-abraded rock surfaces in the Columbia Hills. The convex nature of the spectra in the 432 to $673 \mathrm{~nm}$ range (incorporated into the calculation of the $535 \mathrm{~nm}$ band depth) in the Peace spectra are potentially attributable to sulfates in Peace (sulfates and other non Fe-bearing minerals can have flat to convex spectra in the this wavelength range). Measurements by Spirit's APXS showed that the RAT hole interior of Peace had 12.89 wt. $\% \mathrm{SO}_{3}$ [Ming et al., 2005] which was the highest measured in any rock in Gusev crater to date. Despite this high sulfur content, in Figures $14-16$ the VNIR spectral parameters of the regions of interest within the Peace 
RAT hole consistently plot with plains basalt. Measurements by the APXS and Mössbauer spectrometer indicated that Peace contained ferrous silicates (pyroxenes and olivines) [Morris et al., 2005] as well as the abundant $\mathrm{SO}_{3}$, believed to be in the form of $\mathrm{Mg}$ and/or Ca sulfates. Other Columbia Hills rocks also have higher $\mathrm{SO}_{3}$ than are found in plains basalts [Ming et al., 2005], but, 1) these rocks are not as sulfur-rich as is Peace and, 2) these rocks all display evidence of alteration (evidenced in Pancam spectra by higher $535 \mathrm{~nm}$ band depths and steeper blue-to-red slopes) relative to plains basalts. Peace, with its high sulfur content and relative lack of alteration, represents a unique rock unit in the Columbia Hills. Further discussion of its significance and possible nature is provided by Squyres et al.[2005] and Ming et al.[2005].

\subsubsection{Anomalous rocks identified through SMA}

Using the spectral parameter plots of Figures 14-16, "unusual" rocks detected by the SMA analyses discussed above can be seen in a new light. For example, the "rock 2" class that was detected in the sol 210 and 220 views of the "dark rocks" area, and whose spectrum is shown in Fig. 6 can be seen to resemble the Watchtower type of spectrum with its $900 \mathrm{~nm}$ band minimum, $803 \mathrm{~nm}$ reflectance maximum, and positive slope from the 803 to $1009 \mathrm{~nm}$ bands. The second rock class in the sol 195 "Viera Cairns" scene has high NIR ratio values and a steep (more negative) NIR slope from 754 to $864 \mathrm{~nm}$ plotting at the far end of the Wishstone/Lower West Spur class field while the main rock class in that scene plots in the Wishstone class field but at the end of that field closer to the plains basalt and Peace field.

\subsection{The composition of Columbia Hills rocks: the Pancam perspective}


This section deals with how multispectral evidence from Pancam can be used to help assess the viability of a proposed origin for rocks in the Columbia Hills. We also consider how this multispectral evidence jibes with Mössbauer spectrometer evidence of $\mathrm{Fe}^{3+}$-bearing minerals in some of the same rock classes discussed here.

\subsubsection{A volcaniclastic origin for Columbia Hills rocks}

One of the hypotheses put forward to explain the nature of the rocks found on the West Spur, and perhaps in other parts of the Columbia Hills, is that they are volcaniclastic in nature [Squyres et al., 2005; Rice et al., 2005; Ruff et al., 2005], perhaps equivalent to terrestrial basaltic tuffs. Given that Mössbauer spectrometer measurements, and the Pancam-measured $535 \mathrm{~nm}$ band depths, have indicated differences in the level of oxidation of the rocks on the West Spur versus those on the northwest flank of Husband Hill, it is instructive to compare the spectral parameters of the Columbia Hills rocks to those of a suite of basaltic tuffs with varying degrees of oxidation. Farrand [1991] and Farrand and Singer [1992] examined the VNIR reflectance of tuffs composing basaltic tuff rings and tuff cones in the American Southwest. These are features produced by the explosive interaction of water and magma. Tuff cones are formed largely of juvenile volcanic material and can contain basaltic ash in varying stages of alteration (palagonitization). Figure 19 shows another plot of $535 \mathrm{~nm}$ band depth vs. $900 \mathrm{~nm}$ band depth with Gusev crater rock groups (excluding, for purposes of clarity, the Lower West Spur and Peace measurements since these groups plot with the Wishstone class and plains basalts respectively) plotted over a field of 17 samples from the Pavant Butte tuff cone (located in Mallard County Utah) with varying levels of oxidation (palagonitization). In examining these tuffs, as well as similar samples from the Cerro 
Colorado tuff cone in the Pinacates volcanic field of Sonora, Mexico, Farrand [1991] observed that unaltered to minimally altered tuff and tephra (consisting, at the most unaltered end, entirely of basaltic glass or sideromelane) have band centers closer to 1 $\mu \mathrm{m}$, that highly palagonitized tuffs have band centers closer to $950 \mathrm{~nm}$, and that the unaltered to minimally altered tuff and tephra have deeper band depths than the more highly palagonitized tuff. The sample spectra that were used for the plot in Figure 19 ranged from unaltered to highly palagonitized. The fact that the spread of these points is elongated primarily along the $535 \mathrm{~nm}$ band depth axis shows that most of the spectral variability in the Pavant Butte tuffs is caused by a differences in the fraction of $\mathrm{Fe}^{3+}$ bearing phases which is related to the degree of palagonitization of the tephra. Comparison with Figure 16 shows that most of the changes in the Columbia Hills rocks are in the depth of the $900 \mathrm{~nm}$ band, not in the depth of the $535 \mathrm{~nm}$ band. Figure 20 shows a comparison of NIR ratio vs. the NIR slope from 754 to $864 \mathrm{~nm}$ for these same groups. In this plot, it can be seen that the basalts plot at the high NIR ratio end of the Pavant Butte tuff field, that the Clovis and Watchtower class measurements plot largely with the Pavant Butte tuffs (albeit with slightly less negative to positive NIR slopes), and that the Wishstone class rocks plot largely out of the Pavant Butte tuff field with higher NIR ratios and more negative NIR slopes.

Figures 19 and 20 indicate that the VNIR spectral properties of the Clovis and Watchtower class rocks are largely consistent with those of basaltic tuffs. The higher 535 $\mathrm{nm}$ band depths of these groups (relative to the majority of the Pavant Butte tuffs) could indicate residual dust contamination or that they have a higher fraction of more crystalline $\mathrm{Fe}^{3+}$ phases than are present in the Pavant Butte tuffs. The fact that the 
Wishstone class rocks plot largely out of the tuff field suggests that they are not glassdominated tephras, but could still be volcanic ejecta with a higher fraction of crystalline phases vis-à-vis juvenile volcanic glass or impact melt. A data set of impact derived clastic rocks equivalent to the collection of samples from Pavant Butte was not available; so the hypothesis that the Columbia Hills rocks are derived from impact ejecta can not be tested here in the same way as the volcaniclastic hypothesis. We note that, based on high $\mathrm{Ni}$ as measured by the APXS, the Clovis class has been suggested to be impact ejecta [Ming et al., 2005; Squyres et al., 2005].

It is worth noting here that the frequent occurrence of the relative reflectance maximum in West Spur rock spectra at $673 \mathrm{~nm}$ is somewhat at odds with observations of terrestrial basaltic tuff spectra. Visual examination of VNIR spectra of basaltic tuffs from Pavant Butte and other sites that have erupted basaltic ashes indicates that the reflectance maxima for these sample spectra generally occurs at wavelengths longer than $673 \mathrm{~nm}$ for all but the least altered of the tuff samples. There are, however, exceptions for tuffs that are more abundant in tachylite (partially devitrified basaltic glass) [Farrand, 1991]. The spectra of tachylite-rich tuffs, convolved to Pancam bandpasses, have a shorter wavelength reflectance maximum and a negative slope at wavelengths longer than the relative reflectance maximum. Explaining the Clovis class rocks as tachylite-rich ashflow or ash-fall tuffs is consistent with the observed Pancam spectra, but an origin as glass-rich impact ejecta could also be consistent with the VNIR spectra.

\subsubsection{The presence of goethite and hematite in Columbia Hills rocks}

Results from Spirit's Mössbauer spectrometer have shown that hematite $\left(\mathrm{Fe}_{2} \mathrm{O}_{3}\right)$ and goethite $(\mathrm{FeOOH})$ are present in many of the most highly altered West Spur and 
Husband Hill rocks [Klingelhoefer et al., 2005]. Both hematite and goethite have characteristic spectral features in the Pancam's spectral range, but characteristic hematite and goethite spectra have not been observed. This is potentially due to the fact that other components, including $\mathrm{Fe}^{3+}$ nanophase oxides and $\mathrm{Fe}^{2+}$ - bearing phases, are also present in varying amounts so that the observed spectra are the result of a mixture of several mineral phases. Still, hematite and goethite can be powerful pigmenting agents which can dominate the VNIR reflectance spectrum even if present in small amounts so a discussion of why unambiguous hematite or goethite spectral features are not observed is in order. Several points can be made on this issue. The first is that while pristine examples of these minerals is not observed, the influence of these minerals is observed to some extent. The inflection that is observed at $535 \mathrm{~nm}$ is likely due to the presence of hematite. Also, Watchtower class rocks have a band minimum at $900 \mathrm{~nm}$ and have a positive near-infrared slope between the reflectance maximum (most often at $754 \mathrm{~nm}$ ) and the R7 (1009 nm) band. The Mössbauer spectrometer observation of Watchtower indicated one of the highest fractions of hematite observed among the Columbia Hills rocks examined to date with $31 \%$ of the Fe present residing in hematite [Morris et al., 2005]. Hematite spectra, convolved to Pancam bandpasses, also have a reflectance maximum at $754 \mathrm{~nm}$ and a positive slope from 754 to $1009 \mathrm{~nm}$. The shorter wavelength features of Watchtower and similar rocks do not resemble those of hematite and the 900 $\mathrm{nm}$ band center is longer than the $860 \mathrm{~nm}$ band minimum of hematite. Morris and Golden [1998] showed that physical mixtures of hematite and goethite retained the 860 $\mathrm{nm}$ hematite band center but lessened the $535 \mathrm{~nm}$ band depth. Those experiments were done with a limited number of mixtures and without the possibly confounding influence 
of nanophase iron oxide phases. While laboratory work would be required to conclusively demonstrate concordance of spectral characteristics, conceptually, a mixture of hematite, goethite and nanophase iron oxides could account for the observed Watchtower spectra.

Goethite also has a characteristic reflectance spectrum in VNIR wavelengths recorded by the Pancam. However, the characteristic ${ }^{6} \mathrm{~A}_{1} \rightarrow{ }^{4} \mathrm{~T}_{2 \mathrm{~g}}$ [Sherman and Waite, 1985] feature at $660 \mathrm{~nm}$ (which would be expressed in Pancam spectra by a depressed reflectance in the $\mathrm{L} 3$ band centered at $673 \mathrm{~nm}$ ) has not been unambiguously observed in any of the rocks shown by the Mössbauer spectrometer to have abundant goethite (these include Clovis, Ebenezer, Uchben, Lutefisk, Champagne and Watchtower). The $900 \mathrm{~nm}$ band minima observed in some of these rocks could be, at least in part, an expression of the stronger ${ }^{6} \mathrm{~A}_{1} \rightarrow{ }^{4} \mathrm{~T}_{1 \mathrm{~g}}$ feature [Sherman and Waite, 1985] in goethite which is characteristically expressed as a band minimum at, or near, $900 \mathrm{~nm}$. Also, while these rocks have stronger $535 \mathrm{~nm}$ band depths and steeper 535 to $601 \mathrm{~nm}$ slopes relative to less oxidized Husband Hill Wishstone rocks, the values of these parameters are still not as high as the Gusev crater highly oxidized bright soils (535 $\mathrm{nm}$ band depths typically greater than 0.04 ) or as the red hematite - bearing portions of the Meridiani outcrop (535 $\mathrm{nm}$ band depths greater than 0.05) [Farrand et al., 2005b].

As was noted above, the rocks that contain goethite also contain hematite. Mixtures of hematite and goethite have been observed to mask the well-defined ${ }^{6} \mathrm{~A}_{1} \rightarrow$ ${ }^{4} \mathrm{~T}_{2 \mathrm{~g}}$ band at $660 \mathrm{~nm}$ in goethite [Morris and Golden, 1998]. Another potential explanation for the absence of a depressed reflectance in the $673 \mathrm{~nm}$ band for goethiterich (up to $42 \%$ in Clovis) is that low albedo phases, such as the hypothesized tachylite 
grains, might be masking the goethite absorption features. However, reflectance spectra of physical mixtures of goethite and magnetite convolved to Pancam bandpasses still display a weak depression in the $673 \mathrm{~nm}$ band even with less than $5 \%$ goethite in the mixture [Farrand, unpublished data]; thus, based on this result, the masking by opaque minerals explanation does not account for the observed spectra.

A final possible explanation is that the goethite that has been observed is poorly crystalline. Nanophase to poorly crystalline goethite also lacks a ${ }^{6} \mathrm{~A}_{1} \rightarrow{ }^{4} \mathrm{~T}_{2 \mathrm{~g}}$ band [Morris et al., 2000]. However, the Mössbauer spectra of the goethite-bearing rocks examined by Spirit display sextet features whereas nanophase goethite would display only a doublet. It is still possible that the goethite could be poorly crystalline since such materials still can display a sextet in Mössbauer spectra, but lack a well-defined ${ }^{6} \mathrm{~A}_{1} \rightarrow$ ${ }^{4} \mathrm{~T}_{2 \mathrm{~g}}$ band in reflectance spectra [R.V. Morris, pers. comm.]. Which of these possible explanations for the lack of an observable ${ }^{6} \mathrm{~A}_{1} \rightarrow{ }^{4} \mathrm{~T}_{2 \mathrm{~g}}$ band is the most likely will require further study.

\section{Conclusions}

The spectral mixture analysis used in this study was effective as a means of characterizing the spectral variability recorded in multispectral scenes collected by Spirit in its exploration of the Gusev crater plains and in its initial explorations of the Columbia Hills. The plains of Gusev crater were found to have low spectral variability, which supports other observations of those plains as being dominated by homogeneous basalts with various amounts of dust, or, in the case of Mazatzal, indurated coatings. In contrast, a much higher level of spectral variability was found among the rocks imaged by Pancam at the base of, and on the slopes of, the Columbia Hills. The slopes of the Columbia Hills 
consist of an assortment of in situ and out-of-place rocks. Some scenes recorded the presence of out-of-place rocks of differing compositions. Examples include the sol 159 P2597 scene that contains Pot of Gold along with a plains basalt and the sol 343 P2543 scene with a Husband Hills Wishstone class rock and the plains basalt, Maids Milking. Another scene of this nature could be the sol 220 P2565 view of the "dark rocks" area which imaged the large, typical Clovis class rocks Pico and Toltecs, but also had smaller examples of rocks with a deeper $900 \mathrm{~nm}$ band and elevated $1009 \mathrm{~nm}$ reflectance. The latter rocks were smaller in size and could be explained as float that was mass wasted from higher elevations in the Hills- especially since the spectra of this second rock class resembles the spectra of Watchtower class rocks.

Spectral mixture analysis also proved useful in characterizing those rocks that were affected by brushing or grinding with Spirit's RAT. The fact that RAT brushing or grinding would produce enough of a difference in the reflectance spectra of the materials affected by the RAT to require the addition of more endmembers to SMA demonstrates the influence (and in some instances the lack of influence) of dust covering and/or coatings on rock surfaces, both on the plains and in the Columbia Hills. For RATabraded rocks in the Columbia Hills, some of the dissimilarity between reflectance spectra of RAT-brushed and RAT-ground surfaces could be due to contamination of the latter by RAT cuttings and as Figure $9 \mathrm{~b}$ illustrates, there can be a difference between the reflectance spectra of RAT cuttings and a brushed surface. Another possibility is that there is a coating that is retained by RAT brushing but abraded away by RAT grinding. This could account for the differences in the Uchben RAT-brushed and RAT-ground spectra in Figure 12. 
Examination of VNIR spectral parameters of rock endmembers obtained in this study also illustrates the spectral variability of Columbia Hills rocks relative to plains basalts. In the spectral parameter plots of Figures 14-16 the basalts consistently plot in a relatively tight cluster in spectral parameter space while the Hills rocks have a significantly wider spread. In some of these plots there is a surprisingly good break out of different groupings of rocks measured in different locations on the Columbia Hills. The two broad groupings are the Clovis class of rocks and the Wishstone class. Lower West Spur rocks plot with the Wishstone class although certain Lower West Spur rocks (e.g., Pot of Gold, measurements from Wooly Patch) have the deepest $900 \mathrm{~nm}$ bands and highest $803 \mathrm{~nm} / 904 \mathrm{~nm}$ ratios in this grouping. Watchtower class rocks generally plot with the Clovis class, albeit somewhat askew from the main Clovis class cluster. MiniTES observations indicate that the Watchtower class rocks are distinct in their thermal infrared spectra from Clovis class rocks such as Pico [Ruff et al., 2005]. Measurements from the RAT-ground area on the rock Peace plotted more closely with the plains basalts than did other Husband Hill rocks.

At the time of the writing of this paper, Spirit has just completed examining the rock outcrops on the Cumberland Ridge (Methuselah, Jib Sheet and Larry's Outcrop). We have not been able to fully integrate results from this region with results obtained up to the analysis of the Larry's Lookout region. While Squyres et al. [2005] group many of these rocks into the Watchtower class, preliminary analysis of Pancam spectra indicate that the Methuselah outcrop has VNIR spectral properties similar to the Wishstone class and Lower West Spur unit and that the VNIR spectra of the Jib Sheet outcrop are similar, but distinct from those of Watchtower class rocks. A more detailed analysis of these 
outcrops, and their relation to other rocks in the Columbia Hills, will be the subject of a future paper.

Comparison of the spectral parameters of the Gusev crater rocks with those determined for a suite of basaltic tuffs in various stages of alteration from the Pavant Butte tuff cone in Mallard County, Utah indicate that plains basalts plot in the spectral parameter field defined by the Pavant Butte tuffs. Clovis and Watchtower class rocks also plot largely within this region. However, the Wishstone class (and Lower West Spur) rocks plot largely outside of the space defined by the Pavant Butte tuffs. This is consistent with Mini-TES observations that indicate that the Wishstone class rocks have higher fractions of crystal phases (labradorite, olivine, pyroxenes) than do the Clovis class rocks (which, according to Mini-TES deconvolutions are dominated by glass [Ruff et al., 2005]). Also, in the plot of $535 \mathrm{~nm}$ band depth versus $900 \mathrm{~nm}$ band depth in Figure 19, it can be seen that the greatest variability in the Pavant Butte tuffs is in terms of changes in $535 \mathrm{~nm}$ band depth while in the Columbia Hills rocks, the greatest variability is in terms of changes in $900 \mathrm{~nm}$ band depth. These observations are consistent with all of these rocks being pyroclastic in origin with the Clovis class rocks consisting largely of partially altered, juvenile basaltic ash and with the Wishstone class rocks being ash with higher fractions of crystalline phases. Unfortunately, the existing knowledge base of the VNIR reflectance characteristics of impact ejecta deposits is not as rich as that for pyroclastic deposits. Comminuted basaltic material ejected by impacts could potentially have similar textural and spectral properties to some pyroclastic deposits and the interpretation of the Columbia Hills rocks as agglomerations of comminuted basaltic material derived from impact ejecta are also deemed to be consistent 
with the data although further studies of the reflectance properties of basaltic impact ejecta materials are required to confirm this.

The rock assemblages that make up the Columbia Hills on the floor of Gusev crater are complex, and data returned by the Spirit rover may eventually uncover many of the pieces of the puzzle of the Columbia Hills. Further study of data from multispectral VNIR images returned by Spirit's Pancam as well as from the other Athena science instruments will be required to assemble those pieces into a recognizable whole.

\section{Acknowledgements}

We would like to acknowledge and thank the dedication and professionalism of the Pancam uplink and downlink teams in targeting observations and ensuring the successful receipt of said observations. We thank Richard V. Morris of NASA JSC for helpful conversations and Alexander F.H. Goetz of the University of Colorado for the use of a laboratory spectrometer. This paper was revised according to helpful suggestions by reviewer Robert Howell and an anonymous reviewer. Funding for Athena science team members was provided by NASA contracts through Cornell and the Jet Propulsion Laboratory.

\section{References}

Adams, J.B., M.O. Smith, and A.R. Gillespie (1993), Imaging spectroscopy:

Interpretation based on spectral mixture analysis. In Remote Geochemical Analysis:

Elemental and Mineralogical Composition, edited by C.M. Pieters and P.A.J. Englert

(New York: Cambridge University Press), 145-166. 
Adams, J.B., M.O. Smith, and P.E. Johnson (1986), Spectral mixture modeling: A new analysis of rock and soil types at the Viking Lander site, J. Geophys. Res., 91, 80988112.

Alexander et al. (2005), Pipeline processing of MER data sets. This issue. Arvidson et al. (2005), Overview of Spirit Mars Exploration Rover mission to Gusev Crater: Landing site to the Methuselah outcrop in the Columbia Hills. This issue. Bartlett, P.W., L.E. Carlson, P.C. Chu, K.R. Davis, S. Gorevan, A.G. Kusack, T.M. Myrick, and J.J. Wilson (2005) Summary of Rock Abrasion Tool (RAT) results pertinent to the Mars Exploration Rover science data set, Lunar Planet. Sci. XXXVI, \#2292.

Bell III, J.F. et al. (2005a), Multispectral properties of soil and dust at the Mars Exploration Rover Spirit Gusev Crater site, submitted to J. Geophys. Res., this issue.

Bell III, J.F., J. Joseph, J.N. Sohl-Dickstein, H.M. Arneson, M.J. Johnson, M.T. Lemmon, and D. Savransky, In-flight calibration and performance of the Mars Exploration Rover Panoramic Camera (Pancam) Instruments (2005b), submitted to J. Geophys. Res., this issue.

Bell III, J.F., S.W. Squyres, R.E. Arvidson, H.M. Arneson, D. Bass, D. Blaney, N.

Cabrol, W. Calvin, J. Farmer, W.H. Farrand, W. Goetz, M. Golombek, J.A. Grant, R. Greeley, E. Guinness, A.G. Hayes, M.Y.H. Hubbard, K.E. Herkenhoff, M.J. Johnson, J.R. Johnson, J. Joseph, K.M. Kinch, M.T. Lemmon, R. Li, M.B. Madsen, J.N. Maki, M. Malin, E. McCartney, S. McLennan, H.Y. McSween, Jr. , D.W. Ming, J.E. Moersch, R.V. Morris, E.Z. Noe Dobrea, T.J. Parker, J. Proton, J.W. Rice, Jr., F. Seelos, J. Soderblom, L.A. Soderblom, J.N. Sohl-Dickstein, R.J. Sullivan, M.J. Wolff, 
and A. Wang (2004a), Pancam multispectral imaging results from the Spirit rover at Gusev crater, Science, 305, 800-806.

Bell III, J.F., S.W. Squyres, R.E. Arvidson, H.M. Arneson, D. Bass, W. Calvin, W.H.

Farrand, W. Goetz, M. Golombek, R. Greeley, E. Guinness, A.G. Hayes, M.Y.H.

Hubbard, K.E. Herkenhoff, M.J. Johnson, J.R. Johnson, J. Joseph, K.M. Kinch, M.T.

Lemmon, R. Li, M.B. Madsen, J.N. Maki, M. Malin, E. McCartney, S. McLennan,

H.Y. McSween, Jr., D.W. Ming, R.V. Morris, E.Z. Noe Dobrea, T.J. Parker, J. Proton,

J.W. Rice, Jr., F. Seelos, J.M. Soderblom, L.A. Soderblom, J.N. Sohl-Dickstein, R.J.

Sullivan, C.M. Weitz, and M.J. Wolff (2004b), Pancam multispectral imaging results

from the Opportunity rover at Meridiani Planum, Science, 306, 1703-1709.

Bell III, J.F., S.W. Squyres, K.E. Herkenhoff, J.N. Maki, H.M. Arneson, D. Brown, S.A.

Collins, A. Dingizian, S.T. Elliot, E.C. Hagerott, A.G. Hayes, M.J. Johnson, J.R.

Johnson, J. Joseph, K. Kinch, M.T. Lemmon, R.V. Morris, L Scherr, M. Schwochert,

M.K. Shepard, G.H. Smith, J.N. Sohl-Dickstein, R. Sullivan, W.T. Sullivan, and M.

Wadsworth, The Mars Exploration Rover Athena Panoramic Camera (Pancam)

Investigation (2003), J. Geophys. Res., 108 (E12), doi:10.1029/2003JE002070.

Bell, J.F., W.H. Farrand, J.R. Johnson, and R.V. Morris (2002), Low abundance materials at the Mars Pathfinder Landing Site: An investigation using spectral mixture analysis and related techniques. Icarus, 158, 56-71.

Bell III, J.F., H. Y. McSween Jr., J. A. Crisp, R. V. Morris, S. L. Murchie, N. T. Bridges, J. R. Johnson, D. T. Britt, M.P. Golombek, H. J. Moore, A. Ghosh, J. L. Bishop, R. C. Anderson, J. Brückner, T. Economou, J. P. Greenwood, H. P. Gunnlaugsson, R. M. Hargraves, S. Hviid, J. M. Knudsen, M. B. Madsen, R. Reid, R. Rieder, and L. 
Soderblom, Mineralogic and Compositional Properties of Martian Soil and Dust:

Results From Mars Pathfinder (2000), J. Geophys. Res., 105, 1721-1755.

Blaney, D., et al., Analyses of spectral remote sensing data for rocks and soils (2005), submitted to J. Geophys. Res., this issue.

Boardman, J.W. and F.A. Kruse (1994), Automated spectral analysis: A geologic example using AVIRIS data, north Grapevine Mountains, Nevada. in Proc. $10^{\text {th }}$ Thematic Conf. Geol.Farrand, W.H. and J.C. Harsanyi (1997), "Mapping the distribution of mine tailings in the Coeur d'Alene River Valley, Idaho through the use of a Constrained Energy Minimization technique." Remote Sens., ERIM, Ann Arbor, MI, pp. I-407-418.

Clark, R.N. (1983), Spectral properties of mixtures of montmorillonite and dark carbon grains: Implications for remote sensing of minerals containing chemically and physically adsorbed water, J. Geophys. Res., 88, $10635-10644$.

Crumpler, L., et al. (2005), Field observations and geologic mapping in Navcam and Pancam images, submitted to J. Geophys. Res., this issue.

Farrand, W.H. (2001), Analysis of AVIRIS Data: A Comparison of the Performance of Commercial Software with Published Algorithms. Proceedings of the Tenth JPL Airborne Earth Science Workshop. JPL Publication 02-1, (R.O. Green, ed.), 125-132. Farrand, W.H. (1991), Visible and Near Infrared Reflectance of Tuff Rings and Tuff Cones., University of Arizona, $187 \mathrm{pp}$.

Farrand, W.H., J.F. Bell III, J.R. Johnson, B.C. Clark, B.L. Joliff (2005a), Visible/Near Infrared spectral characterization of in situ outcrops at Meridiani Planum as observed by the Mars Exploration Rover Opportunity, Lunar Planet. Sci. XXXVI, \#2082. 
Farrand, W.H. et al. (2005b) Visible and Near Infrared analysis of rock outcrops examined by the Mars Exploration Rover Opportunity at Meridiani Planum: Spectral properties and stratigraphy, manuscript under preparation for J. Geophys. Res..

Farrand, W.H., J.R. Johnson, J.F. Bell III (2001), N-Dimensional visualization and spectral mixture analysis applied to Imager for Mars Pathfinder data: Detection and mapping of rocks and soils. Lunar Planet. Sci. XXXII, \#1656.

Farrand, W.H. and J.C. Harsanyi (1997), Mapping the distribution of mine tailings in the Coeur d'Alene River Valley, Idaho through the use of a Constrained Energy Minimization technique. Remote Sens. Env., 59, 64-76.

Farrand, W.H. and R.B. Singer (1992), Alteration of hydrovolcanic basaltic ash: Observations with visible and near-infrared spectrometry. J. Geophys. Res., 97, $17,393-17,408$.

Gellert, R., R. Rieder, J. Brückner, B. Clark, G. Dreibus, G. Lugmair, D. Ming, H. Waenke, A.Yen, J. Zipfel et al. (2005), The Alpha Particle X-Ray Spectrometer (APXS): Results from Gusev Crater and Calibration Report, submitted to J. Geophys. Res., this issue.

Gillespie, A.R., A.B. Kahle, R.E. Walker (1986), Color enhancement of highly correlated images: I. Decorrelation and HSI contrast stretches. Remote Sens. Env., 20, 209-235.

Green, A.A., M. Berman, P. Switzer, M.D. Craig (1988), A transformation for ordering multispectral data in terms of image quality with implications for noise removal. IEEE Trans. Geosci. Remote Sens., 26, 65-74. 
Harsanyi, J.C. (1993), Detection and classification of subpixel spectral signatures in hyperspectral image sequences, PhD thesis, Univ. of Maryland Baltimore County, 116 pp.

Johnson, J.R., W.M. Grundy, M.T. Lemmon, J.F. Bell III, M.J. Johnson, R. Deen, R.E. Arvidson, W.H. Farrand, E. Guinness, K.E. Herkenhoff, F. Seelos IV, J. Soderblom, S.W. Squyres, and M.J. Wolff (2005), Spectrophotometric properties of materials observed by Pancam on the Mars Exploration Rovers: 1. Spirit, submitted to $J$. Geophys. Res., this issue.

Klingelhoefer, G., et al., Mössbauer mineralogy of the Gusev landing site and Columbia Hills (2005), submitted to J. Geophys. Res., this issue.

Knudson, A., et al. (2005), Disturbed soil mineralogy from Mini-TES observations, submitted to J. Geophys. Res., this issue.

Lemmon, M.T. et al. (2004) Atmospheric imaging results from the Mars Exploration Rovers: Spirit and Opportunity, Science, 306, 1753-1756.

McSween, H.Y. et al. (2005), Characterization and petrologic interpretation of olivinerich basalts at Gusev Crater, Mars, submitted to J. Geophys. Res., this issue.

McSween, H. Y., R. E. Arvidson, J. F. Bell III, D. Blaney, N. A. Cabrol, P. R. Christensen, B. C. Clark, J. A. Crisp, L. S. Crumpler, D. J. Des Marais, J. D. Farmer, R. Gellert, A. Ghosh, S. Gorevan, T. Graff, J. Grant, L. A. Haskin, K. E. Herkenhoff, J. R. Johnson, B. L. Jolliff, G. Klingelhoefer, A. T. Knudson, S. McLennan, K. A. Milam, J. E. Moersch, R. V. Morris, R. Rieder, S. W. Ruff, P. A. de Souza, Jr., S. W. Squyres, H. Wänke, A. Wang, M. B. Wyatt, A. Yen, and J. Zipfel, Basaltic rocks analyzed by the Spirit Rover in Gusev crater (2004), Science, 305, 842-845. 
Ming, D.W. et al. (2005), Geochemical and mineralogical indicators for aqueous processes in the Columbia Hills of Gusev Crater, Mars, submitted to J. Geophys. Res., this issue.

Morris, R. V. et al. (2005), Mössbauer mineralogy of rock and soil at Gusev Crater: Spirit's journey through weakly altered olivine basalt on the Gusev Plains and pervasively altered basalt in the Columbia Hills, submitted to J. Geophys. Res., this issue.

Morris, R.V. and D.C. Golden (1998) Goldenrod pigments and the occurrence of hematite and possibly goethite in the Olympus-Amazonis region of Mars, Icarus, 134, $1-10$.

Ramsey, M.S. and P.R. Christensen (1998), Mineral abundance determination: Quantitative deconvolution of thermal emission spectra, J. Geophys. Res., 103, 577596.

Ray, T.W. and B.C. Murray (1996), Nonlinear spectral mixing in desert vegetation, Remote Sens. Environ., 55, 59-64.

Reid, R.J., P.H. Smith, M. Lemmon, R. Tanner, M. Burkland, E. Wegryn, J. Weinberg, R. Marcialis, D.T. Britt, N. Thomas, R. Kramm, A. Dummel, D. Crowe, B.J. Bos, J.F. Bell III, P. Rueffer, F. Gliem, J.R. Johnson, J.N. Maki, K.E. Herkenhoff, and R.B. Singer (1999), Imager for Mars Pathfinder (IMP) image calibration, J. Geophys. Res., $104,8907-8926$.

Research Systems, Inc. (2004), ENVI v. 4.1 Users Guide.

Rice, J. et al. (2005), submitted to J. Geophys. Res., this issue. 
Ruff, S. W., P. R. Christensen, D. L. Blaney, W. H. Farrand, J. R. Johnson, J. Michalski, J. E. Moersch, and S. Wright (2005), The rocks of Gusev Crater as viewed by the Mini-TES instrument, submitted to J. Geophys. Res., this issue.

Sherman, D.M. and T.D. Waite (1985), Electronic spectra of $\mathrm{Fe}^{3+}$ oxides and oxide hydroxides in the near IR and near UV, Am. Mineral., 70, 1262-1269.

Singer, R.B. and T.B. McCord (1979), Mars: Large scale mixing of bright and dark surface materials and implications for analysis of spectral reflectance, Proc. Lunar Sci. Conf., 10, 1835-1848.

Smith, M.O., S.L. Ustin, J.B. Adams, and A.R. Gillespie (1990), "Vegetation in deserts: 1. A regional measure of abundance from multispectral images". Remote Sens. Env. 31, 1-26.

Sohl-Dickstein, J., J.R. Johnson, W.M. Grundy, E.A. Guiness, T. Graff, M.K. Shepard, R.E. Arvidson, J.F. Bell III, P.R. Christensen, R.V. Morris (2005), Modeling Visible/Near-Infrared photometric properties of dustfall on a known substrate, Lunar Planet Sci. XXXVI, \#2235.

Squyres, S.W. et al. (2005), Origin and evolution of the Columbia Hills, Gusev Crater, Mars, submitted to J. Geophys. Res., this issue.

Squyres, S. W. et al.(2004), The Spirit rover's Athena science investigation at Gusev Crater, Mars, Science, 305, 794-799.

Squyres, S. W., R. E. Arvidson, E. T. Baumgartner, J. F. Bell, P. R. Christensen, S. Gorevan, K. E. Herkenhoff, G. Klingelhofer, M. B. Madsen, R. V. Morris, R. Rieder, R. A. Romero (2003), Athena Mars rover science investigation, J. Geophys. Res., 108(E12), 8062, doi:10.1029/2003JE002121. 
Thomas, N. W.J. Markiewicz, R.M, Sablotny, M.W. Wuttke, H.U. Keller, J.R. Johnson, R.J. Reid, and P.H. Smith (1999), The color of the Martian sky and its influence on the illumination of the Martian surface, J. Geophys. Res., 104, 8795-8808.

Wang, A., R.L. Korotev, B.L. Joliff, L.A. Haskin, L. Crumpler, W.H. Farrand, K.E. Herkenhoff, P. de Souza, A.G. Kusack (2005) Evidence of phyllosilicates in Wooly Patch, an altered rock encountered at West Spur, Columbia Hills by Spirit rover, submitted to J. Geophys. Res., this issue.

\section{Figure Captions}

Figure 1. a. First four Minimum Noise Fraction (MNF) transformation bands obtained from a low spectral variability scene. The image shown is the sol 297 P2546 left eye camera view of the undisturbed rock "Lutefisk". b. First six MNF transformation bands obtained from a high spectral variability scene. The image shown is the sol 87 P2530 view of the RAT-ground and RAT-brushed surfaces on the rock "Mazatzal". This scene is also referenced in Fig. 8.

Figure 2. Two dimensional representation of a plot of the first three MNF bands of the Sol 297 P2546 left eye image sequence. The triangular shape is indicative of three endmembers and an intrinsic dimensionality of two.

Figure 3. Results of SMA on a simple, low spectral variability scene. A. Sol 76 P2567 L2 $(753 \mathrm{~nm})$ view centered on the rock "Mazatzal". B. "Shade" fraction image. C. "Bright" fraction image. Bright image endmember drawn from bright drifts in the scene. D. "Rock" fraction image. E. RMS error image. Some bright rock coatings were not well modeled by the three endmember model and remain bright in this image. 
Figure 4. a. R5, 2, $1(900,754,436 \mathrm{~nm})$ composite of subsection of Sol 159 P2597 image sequence centered on the rock "Pot of Gold". b. n-D data cloud of first three MNF bands of right eye data. Note five to six distinct spurs. The spur circled in cyan corresponds to a plains basalt in the far corner of the scene (not shown in Fig. 4a). The spur circled in green corresponds to dark patches on Pot of Gold with distinct $900 \mathrm{~nm}$ bands. The spur circled in yellow corresponds to shade. The spur circled in red corresponds to bright materials and the purple and maroon ellipses correspond to another rock elsewhere in the scene (again, not shown in Fig. 4a). c. Plot of combined eye spectra of Pot of Gold dark patches and plains basalt in the P2597 scene.

Figure 5. a. Plot of first three MNF bands derived from right eye images from sol 195 sequence P2548. The main rock vertex is tipped in green and the spur from the main cloud is colored in magenta. b. R2 (754 nm) band from the P2548 scene centered on the rock Viera Cairns. The green ellipse surrounds those pixels corresponding to the green tipped data cloud vertex in Fig. 5a. The magenta ellipse surrounds those pixels corresponding to the spur colored in magenta in Fig. 5a. c. Composite of CEM fraction images, all stretched between 0 and 1 with the red channel assigned to the fraction image corresponding to the endmember obtained from the magenta colored spur in Fig. 5a; green is assigned to the fraction image derived from the main rock endmember, and blue is the fraction image derived from the bright material image endmember. d. Combined eye spectra of the two rock endmembers from this scene.

Figure 6. Combined eye spectra of the two rock endmembers from the sol 220 P2565 scene that includes the rocks "Pico" and "Toltecs". The image pixels from the primary rock endmember were extracted from the rock Pico.

Figure 7. a. Sol 343, L2 (753 nm) band of P2575 image sequence. Rectangle encloses upper portion of the rock "Maids Milking". Ellipse encloses upper portion of a Husband Hill clastic rock. Triangle encloses "small rock" of indeterminate composition. b. Plot of spectra from rocks referenced above. The Hills rock has a longer wavelength reflectance maximum and a shorter band center marked by the upper arrow. The basalt, 
Maids Milking, has a shorter wavelength reflectance maximum and a longer band center marked by the lower arrow. The "small rock" appears to be a basalt since it too has a shorter wavelength reflectance maximum and a longer band center.

Figure 8. a. R7 (754 nm) view of subsection of sol 87 P2530 view of rock Mazatzal after RAT grinding and brushing. $\mathbf{b}$ - e. Fraction images from four endmember SMA of this right eye image sequence: shade, bright material, RAT cuttings, and natural rock. f. RMS error image produced from this four endmember SMA.

Figure 9. a. Decorrelation stretch composite of sol 226 P2569 bands L3, 5, and 7 (673, 535 , and $432 \mathrm{~nm}$ ) on the RAT abraded surface of the rock "Clovis". Note color difference between RAT cuttings on the left and brushed rock surface on the right. b.spectra of Clovis brushed surface and Clovis RAT cuttings, brushed surface spectrum offset upwards by 0.02 for clarity.

Figure 10. a. Sol 238 P2585 L2 $(753 \mathrm{~nm})$ view of rock "Ebenezer after RAT grinding and brushing. Representative dark natural rock surfaces are circled. b. SMA fraction image of the RAT hole interior endmember showing high fractions on the circled dark rock surfaces.

Figure 11. Sol $286 \mathrm{MI}$ mosaic of the hole ground by the RAT into Uchben. The incompletely RAT'ed depression that has a reflectance spectrum that corresponds to the brushed area on Uchben is indicated with the arrow.

Figure 12. Pancam spectra from sol $293 \mathrm{P} 2543$ view of the RAT-abraded Uchben. Combined eye spectra shown of the Uchben brushed spot (spectrum offset downwards by 0.03 for clarity), and dark and light toned areas in RAT hole. 
Figure 13. Representative Gusev crater rock endmember spectra. a. Examples of each of the groupings presented in a single plot. Spectra offset for clarity. b. Representative plains basalt spectra ("Sarah" offset upwards by 0.02). c. Representative spectra of Lower West Spur rocks (sol 200 scuffs offset upwards by 0.03, "Mastodon” offset downwards by 0.02$)$. d. Representative spectra from the largest clean rock surfaces on the West Spur ("Uchben" offset upwards by 0.03 , "Pico" offset downwards by 0.02, Sol 210 unnamed rock offset upwards by 0.01 ). e. Representative spectra from rocks on the west flank of Husband Hill ("Alligator" offset upwards by 0.05, Sol 343 unnamed rock offset upwards by 0.02 , Wishstone RATted offset downwards by 0.02). f. Representative spectra from rocks in the Larry's Lookout region ("Lighthouse" offset upwards by 0.05 , RATted Watchtower offset upwards by 0.02 , Watchtower offset downwards by 0.02 ).

Figure 14. Plot of NIR ratio (803 nm / $904 \mathrm{~nm})$ vs. NIR slope (from 754 to $864 \mathrm{~nm}$ ) for representative Gusev Crater rock surfaces.

Figure 15. Plot of NIR ratio (803 nm / $904 \mathrm{~nm})$ vs. the NIR slope from 754 to $1009 \mathrm{~nm}$ for representative Gusev Crater rock surfaces.

Figure 16. Plot of $535 \mathrm{~nm}$ band depth vs. $900 \mathrm{~nm}$ band depth. Dashed vertical line marks $535 \mathrm{~nm}$ band depth of 0.009. Highly oxidized Clovis, Watchtower and some Wishstone class rocks have $535 \mathrm{~nm}$ band depths greater than 0.009. Plains basalts, Lower West Spur, some Wishstone class rocks and Peace have lower $535 \mathrm{~nm}$ band depths.

Figure 17. Plot of $\mathrm{Fe}^{3+} / \mathrm{Fe}_{\text {Total }}$ as measured by Spirit's Mössbauer spectrometer (MB) versus $535 \mathrm{~nm}$ band depth for areas in the Columbia Hills that were subjected to in situ examinations.

Figure 18. a. Spectra from a dark patch and intermediate toned areas (indicated in Fig. 18b) within the RAT-ground area on the rock Peace. Spectra from the sol 381 P2543 image sequence. b. Enlarged subsection from the sol 381 P2543 R3 (803 nm) band with 
spectra extraction locations indicated by circle for dark patch and arrows for intermediate toned areas.

Figure 19. Plot of $535 \mathrm{~nm}$ band depth vs. $900 \mathrm{~nm}$ band depth for Gusev crater rocks and a set of 17 samples of basaltic tuff from the Pavant Butte tuff cone in various stages of alteration (palagonitization). The vertical line used in Figure 16 has been inserted here to facilitate comparison with that figure.

Figure 20. Plot of NIR ratio (803 nm / $904 \mathrm{~nm})$ vs. NIR slope from 754 to $864 \mathrm{~nm}$ for Gusev crater rocks and Pavant Butte tuffs.

\section{Tables}

Table 1. Pancam band names, centers and FWHM widths

\begin{tabular}{|l|c|c|}
\hline Band & Center $(\mathrm{nm})$ & FWHM Width(nm) \\
\hline L7 & 432 & 25 \\
\hline L6 & 482 & 27 \\
\hline L5 & 535 & 19 \\
\hline L4 & 601 & 17 \\
\hline L3 & 673 & 16 \\
\hline L2 & 753 & 20 \\
\hline R1 & 436 & 25 \\
\hline R2 & 754 & 19 \\
\hline R3 & 803 & 20 \\
\hline R4 & 864 & 17 \\
\hline R5 & 904 & 25 \\
\hline R6 & 934 & 24 \\
\hline
\end{tabular}




\begin{tabular}{|l|c|c|}
\hline R7 & 1009 & 28 \\
\hline
\end{tabular}

Table 2. Description of Spectral Parameters used in this study

\begin{tabular}{|l|l|}
\hline Parameter & Description \\
\hline $535 \mathrm{~nm}$ band depth & {$\left[\left(0.570 \times \mathrm{R}^{*}{ }_{432}\right)+\left(0.430 \times \mathrm{R}^{*}{ }_{673}\right)\right]-\mathrm{R}^{*}{ }_{535}$} \\
\hline 535 to $601 \mathrm{~nm}$ slope & $\left(\mathrm{R}^{*} 601-\mathrm{R}^{*}{ }_{535}\right) /(601-535)$ \\
\hline $900 \mathrm{~nm}$ band depth & {$\left[\left(0.510 \times \mathrm{R}^{*}{ }_{800}\right)+\left(0.43 \times \mathrm{R}^{*}{ }_{1009}\right)\right]-\mathrm{R}^{*}{ }_{900}$} \\
\hline $800 \mathrm{~nm} / 900 \mathrm{~nm}$ ratio & $\mathrm{R} 3 / \mathrm{R} 5(800 \mathrm{~nm}$ band $/ 900 \mathrm{~nm}$ band $)$ \\
\hline 754 to $864 \mathrm{~nm}$ slope & $\left(\mathrm{R}^{*} 864-\mathrm{R}^{*}{ }_{754}\right) /(864-754)$ \\
\hline 754 to $1009 \mathrm{~nm}$ slope & $\left(\mathrm{R}^{*}{ }_{1009}-\mathrm{R}^{*}{ }_{754}\right) /(1009-754)$ \\
\hline
\end{tabular}

Table 3. Comparison of spectral parameters for sol 238 P2585 image sequence centered on the RAT-brushed rock Ebenezer

\begin{tabular}{|l|l|l|l|l|}
\hline & $\begin{array}{l}535 \mathrm{~nm} \text { Band } \\
\text { Depth }\end{array}$ & $\begin{array}{l}\text { Standard } \\
\text { Deviation }\end{array}$ & $\begin{array}{l}535 \text { to } 601 \mathrm{~nm} \\
\text { slope }\end{array}$ & $\begin{array}{l}\text { Standard } \\
\text { Deviation }\end{array}$ \\
\hline Ebenezer brushed & 0.012437 & 0.002511 & 0.000733 & 0.000083 \\
\hline Undisturbed surface & 0.014222 & 0.003566 & 0.000882 & 0.000081 \\
\hline Bright Dust endmember & 0.044936 & 0.003014 & 0.001703 & 0.000074 \\
\hline Scene Minimum & -0.002739 & 0.008159 & 0.000162 & 0.000247 \\
\hline Scene Maximum & 0.054631 & 0.008159 & 0.001978 & 0.000247 \\
\hline
\end{tabular}

Table 4. Most notable spectral characteristics of rock spectral classes. NIR slope is defined here as the slope from 754 to $864 \mathrm{~nm}$.

\begin{tabular}{|l|l|l|l|l|}
\hline Area & $\begin{array}{l}\text { Band } \\
\text { Minimum(nm) }\end{array}$ & $\begin{array}{l}\text { Reflectance } \\
\text { Maximum(nm) }\end{array}$ & $\begin{array}{l}\text { Other relevant } \\
\text { features }\end{array}$ & Examples \\
\hline $\begin{array}{l}\text { Plains } \\
\text { basalts }\end{array}$ & 934 & 673 to 754 & $\begin{array}{l}\text { Intermediate NIR } \\
\text { slope }\end{array}$ & $\begin{array}{l}\text { Humphrey, } \\
\text { Mazatzal }\end{array}$ \\
\hline $\begin{array}{l}\text { Base of } \\
\text { West Spur }\end{array}$ & 934 & 754 & Steep NIR slope & $\begin{array}{l}\text { Pot of Gold, } \\
\text { Wooly Patch }\end{array}$ \\
\hline West Spur & 934 to 1009 & 673 & Shallow NIR slope & Frio, Pico \\
\hline $\begin{array}{l}\text { Husband } \\
\text { Hill }\end{array}$ & 934 & $\begin{array}{l}754 \text { to co-equal } \\
673 \text { to } 754\end{array}$ & Steep NIR slope & $\begin{array}{l}\text { Wishbone, } \\
\text { LaBrea }\end{array}$ \\
\hline $\begin{array}{l}\text { Larry's } \\
\text { Lookout }\end{array}$ & 900 & 754 to 803 & $\begin{array}{l}\text { Shallow NIR slope, } \\
\text { positive slope from } \\
754 \text { to 1009 nm }\end{array}$ & Watchtower \\
\hline
\end{tabular}


Table 5. Spectral parameters plotted in Figures $15-17$ were extracted from averages of pixels on the rocks listed here.

\begin{tabular}{|c|c|}
\hline \multirow[t]{5}{*}{ Plains Basalts } & Sol 54 P2529 Humphrey \\
\hline & Sol 60 P2597 Humphrey (undisturbed) \\
\hline & Sol 87 P2530 Mazatzal RAT hole interior \\
\hline & Sol 159 P2597 unnamed basalt \\
\hline & Sol 343 P2575 Maids Milking \\
\hline \multirow{6}{*}{$\begin{array}{l}\text { Base of Husband } \\
\text { Hill's West Spur }\end{array}$} & Sol 159 P2598 Pot of Gold dark patches \\
\hline & Sol 195 P2548 Viera Cairns \\
\hline & Sol 195 P2548 second rock type with deeper $900 \mathrm{~nm}$ band depth \\
\hline & Sol 200 P2556 Mastodon RAT hole interior \\
\hline & Sol 200 P2556 Sabre RAT hole interior \\
\hline & Sol 200 P2556 scuffs \\
\hline \multirow{13}{*}{$\begin{array}{l}\text { West Spur of } \\
\text { Husband Hill }\end{array}$} & Sol 220 P2565 Pico \\
\hline & Sol 226 P2569 Clovis brushed \\
\hline & Sol 227 P2572 Frio \\
\hline & Sol 238 P2585 Ebenezer RAT hole \\
\hline & Sol 238 P2585 unnamed rock near Ebenezer \\
\hline & Sol 269 P2534 Palenque \\
\hline & Sol 269 P2534 unnamed rock with deeper $900 \mathrm{~nm}$ band depth \\
\hline & Sol 269 P2534 multiple rock surfaces \\
\hline & Sol 291 P2420 Palenque dark surfaces \\
\hline & Sol 293 P2543 Uchben brushed \\
\hline & Sol 293 P2543 Uchben RAT hole interior \\
\hline & Sol 304 P2553 Lutefisk upper brush spot \\
\hline & Sol 304 P2553 Lutefisk lower brush spot \\
\hline \multirow{7}{*}{$\begin{array}{l}\text { Husband Hill } \\
\text { northwest flank }\end{array}$} & Sol 332 P2563 Wishbone \\
\hline & Sol 337 P2569 Wishstone RAT hole interior \\
\hline & Sol 343 P2575 unnamed rock \\
\hline & Sol 343 P2574 La Brea \\
\hline & Sol 369 P2534 unnamed rocks near Peace \\
\hline & Sol 381 P2543 unnamed rock near Peace \\
\hline & Sol 386 P2546 brushed Alligator \\
\hline \multirow[t]{2}{*}{ Peace } & Sol 381 P2543 Peace RAT hole interior dark patch \\
\hline & Sol 381 P2543 Peace RAT hole interior several spots \\
\hline \multirow[t]{4}{*}{ Larry’s Lookout } & Sol 409 P2562 Watchtower undisturbed \\
\hline & Sol 414 P2564 unnamed rock \\
\hline & Sol 419 P2574 Watchtower RAT hole interior \\
\hline & Sol 419 P2574 Watchtower undisturbed areas \\
\hline
\end{tabular}

Table 6. Spectral parameters of rock classes. Mean values from representative endmember spectra in each group (listed in Table 4) are followed by standard deviations of the mean. 


\begin{tabular}{|l|l|l|l|l|l|}
\hline Rock unit & $\begin{array}{l}535 \text { to } 601 \\
n m \text { slope }(\times \\
\left.10^{-4}\right)\end{array}$ & $\begin{array}{l}535 \mathrm{~nm} \text { Band } \\
\text { Depth } \\
\left(\times 10^{-3}\right)\end{array}$ & $\begin{array}{l}754 \text { to 864 } \\
\mathrm{nm} \text { slope } \\
\left(\times 10^{-5}\right)\end{array}$ & $\begin{array}{l}\text { 900 } \mathrm{nm} \text { Band } \\
\text { Depth }\left(\times 10^{-3}\right)\end{array}$ & $\begin{array}{l}803 \mathrm{~nm} / 904 \\
\mathrm{~nm}\end{array}$ \\
\hline $\begin{array}{l}\text { Adirondack } \\
\text { Plains } \\
\text { Basalts }\end{array}$ & $3.93 \pm 0.81$ & $14.0 \pm 3.9$ & $-5.42 \pm 3.4$ & $5.23 \pm 2.6$ & $1.070 \pm 0.023$ \\
\hline $\begin{array}{l}\text { Lower West } \\
\text { Spur }\end{array}$ & $7.61 \pm 0.77$ & $5.42 \pm 4.2$ & $-12.7 \pm 4.7$ & $15.3 \pm 3.6$ & $1.137 \pm 0.026$ \\
\hline $\begin{array}{l}\text { West Spur } \\
\text { Clovis }\end{array}$ & $7.44 \pm 0.10$ & $18.4 \pm 3.4$ & $-1.48 \pm 3.5$ & $3.36 \pm 2.8$ & $1.046 \pm 0.024$ \\
\hline $\begin{array}{l}\text { Husband } \\
\text { Hill } \\
\text { Wishstone }\end{array}$ & $7.07 \pm 0.84$ & $11.4 \pm 3.2$ & $-12.6 \pm 4.8$ & $7.22 \pm 2.9$ & $1.121 \pm 0.030$ \\
\hline $\begin{array}{l}\text { Husband } \\
\text { Hill Peace }\end{array}$ & $1.87 \pm 0.12$ & $-2.26 \pm 2.3$ & $-6.00 \pm 2.8$ & $6.06 \pm 1.9$ & $1.091 \pm 0.022$ \\
\hline $\begin{array}{l}\text { Larry's } \\
\text { Lookout }\end{array}$ & $7.53 \pm 0.86$ & $13.2 \pm 3.8$ & $-2.60 \pm 3.9$ & $6.85 \pm 3.5$ & $1.028 \pm 0.023$ \\
\hline
\end{tabular}




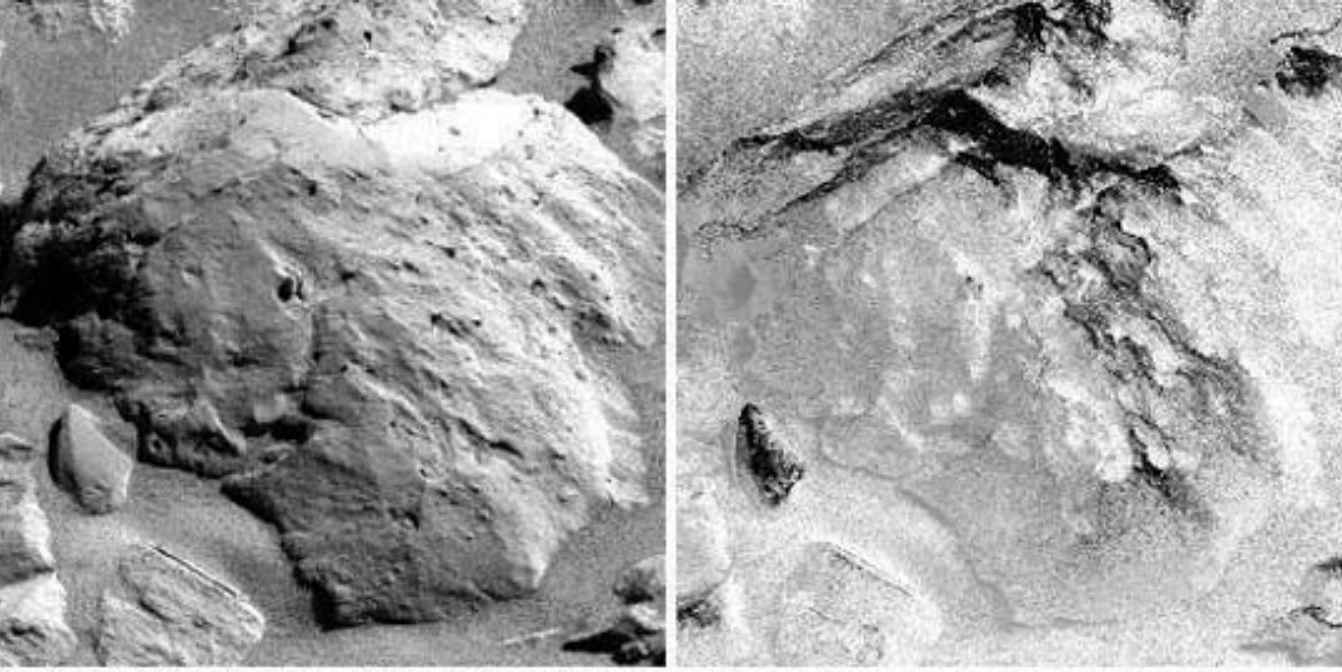

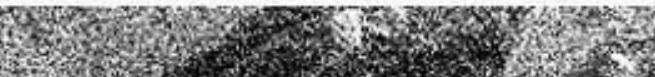

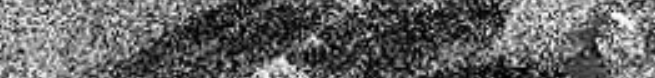

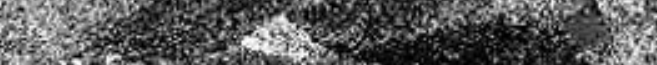

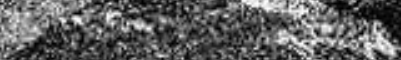

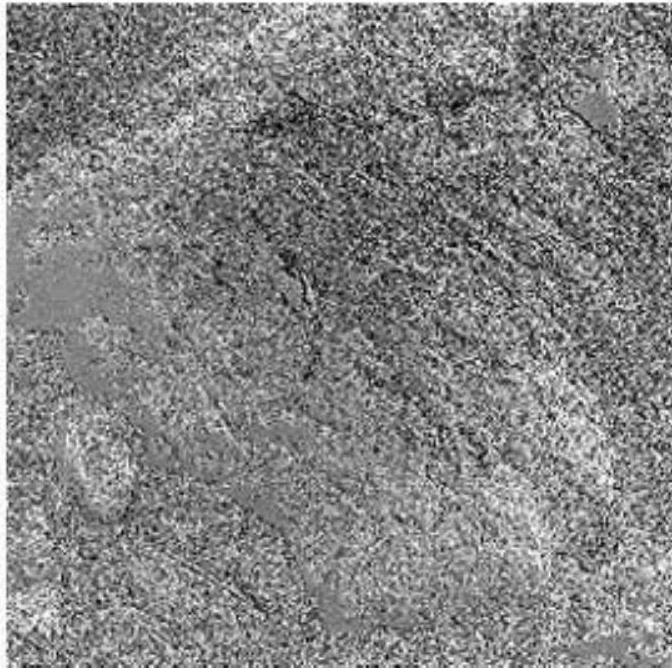

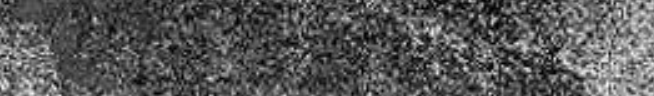

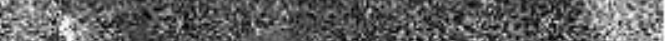

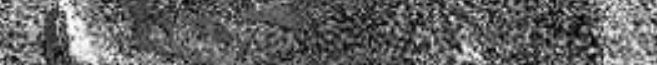

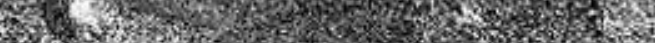

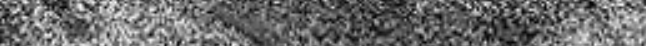

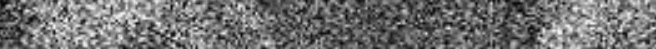

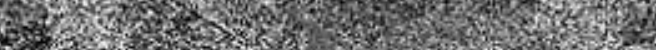

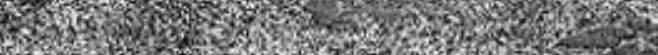

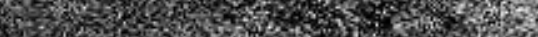

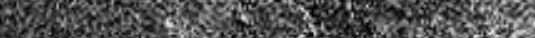

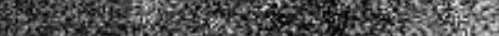

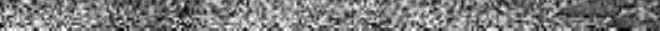





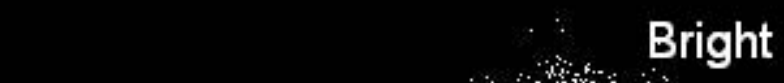
wis \% w . 1) $\because$ 桨 1.5e

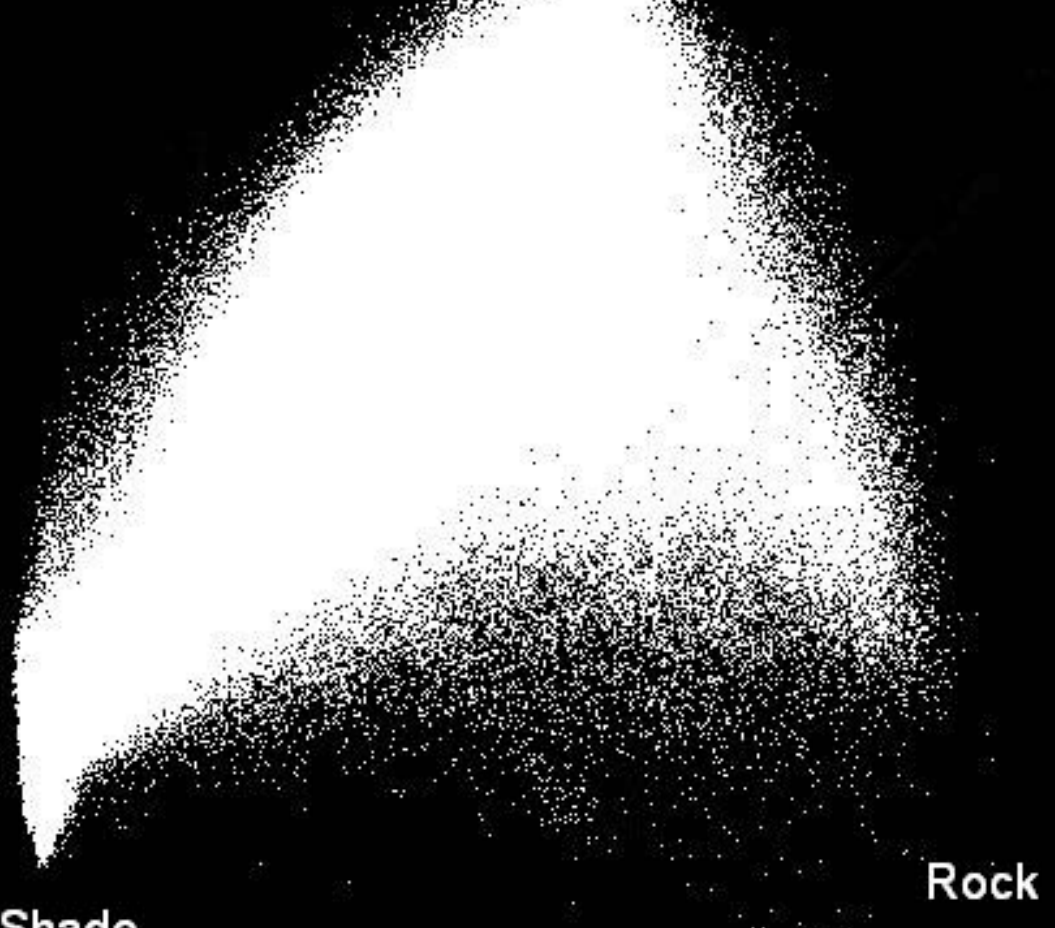

Shade 

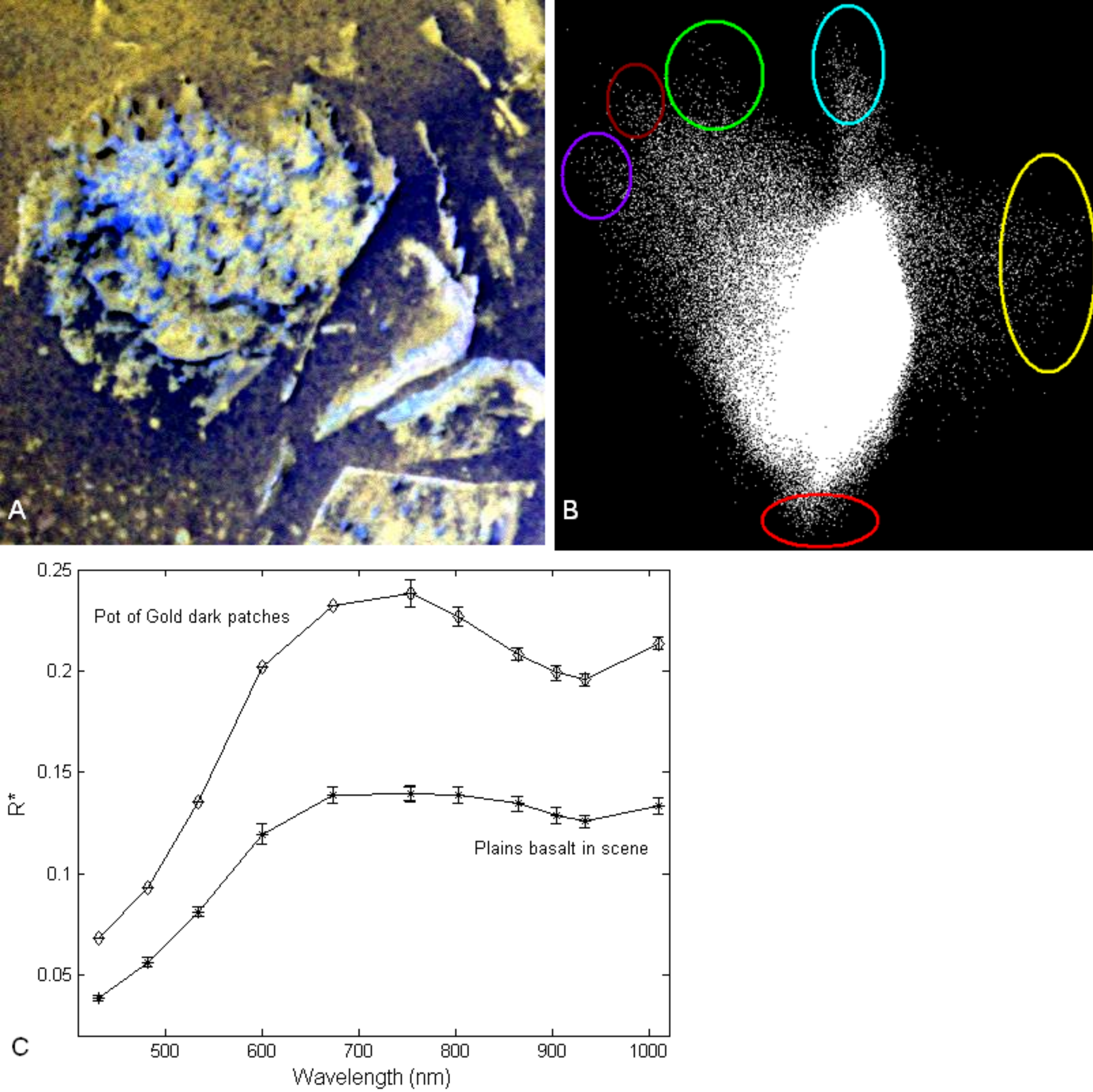

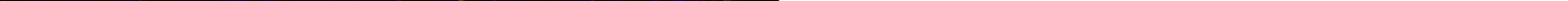


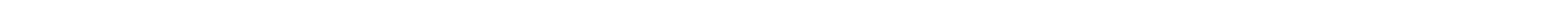




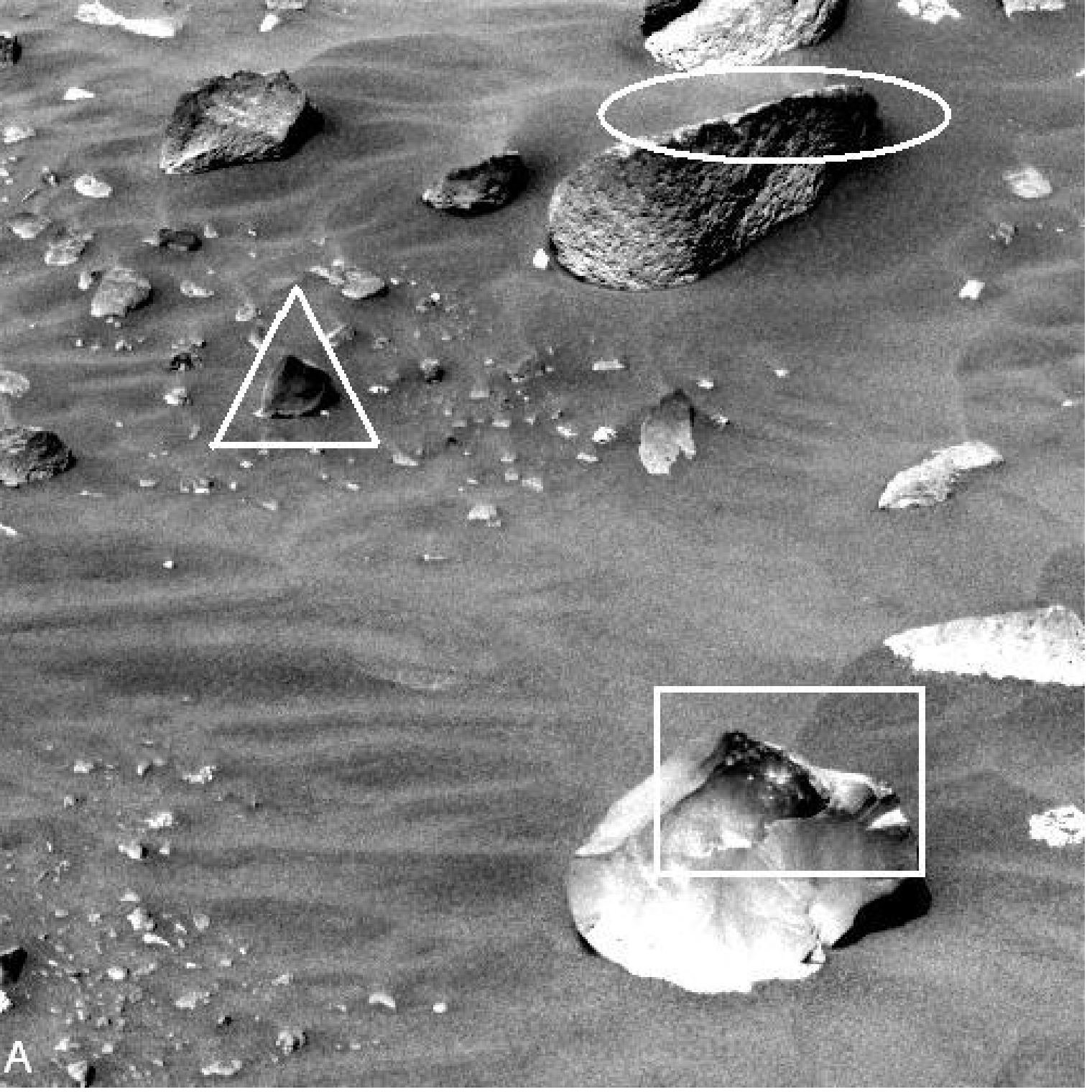

A $6: 2$

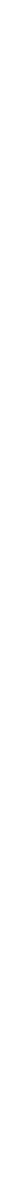


B
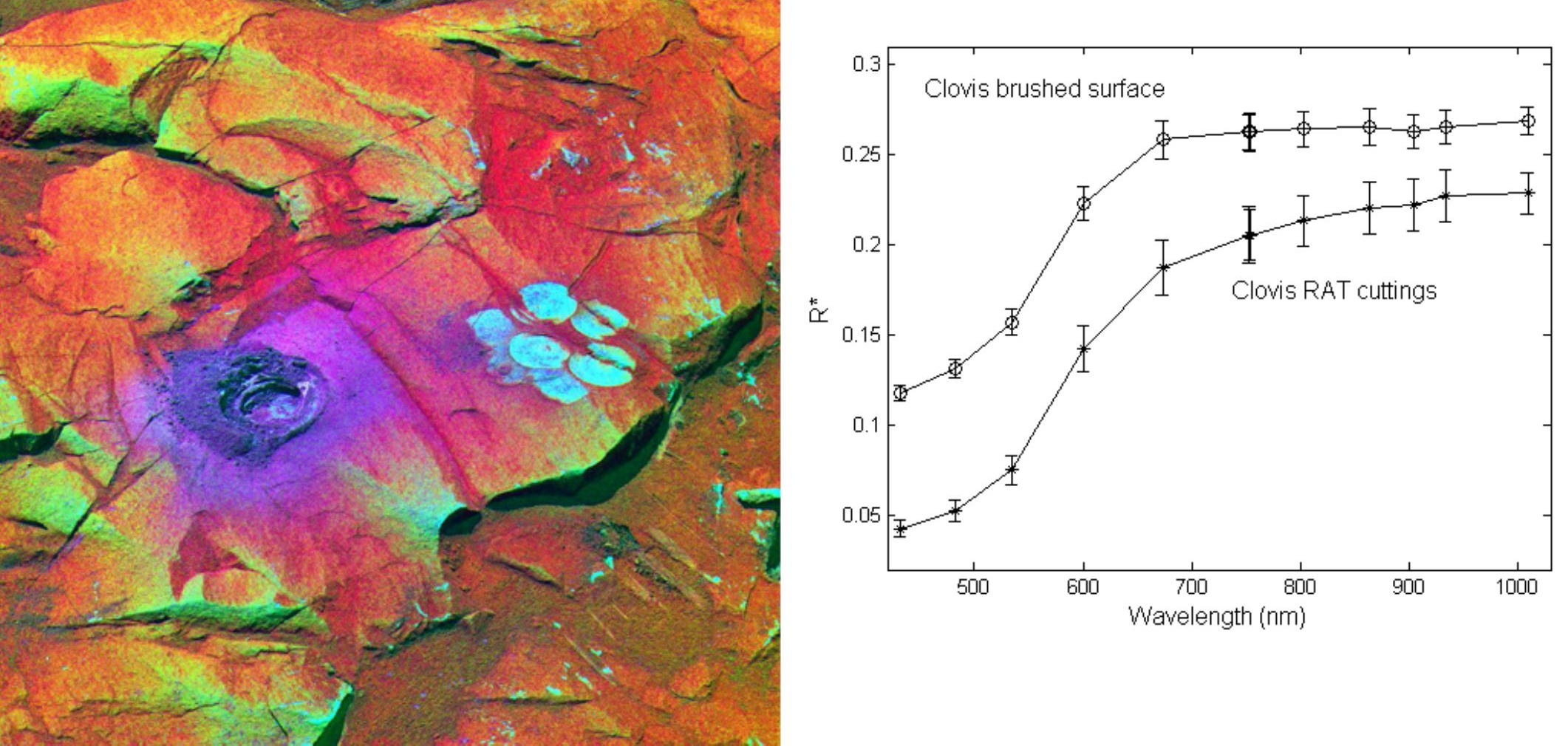


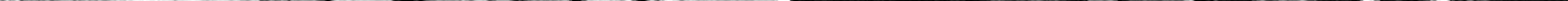




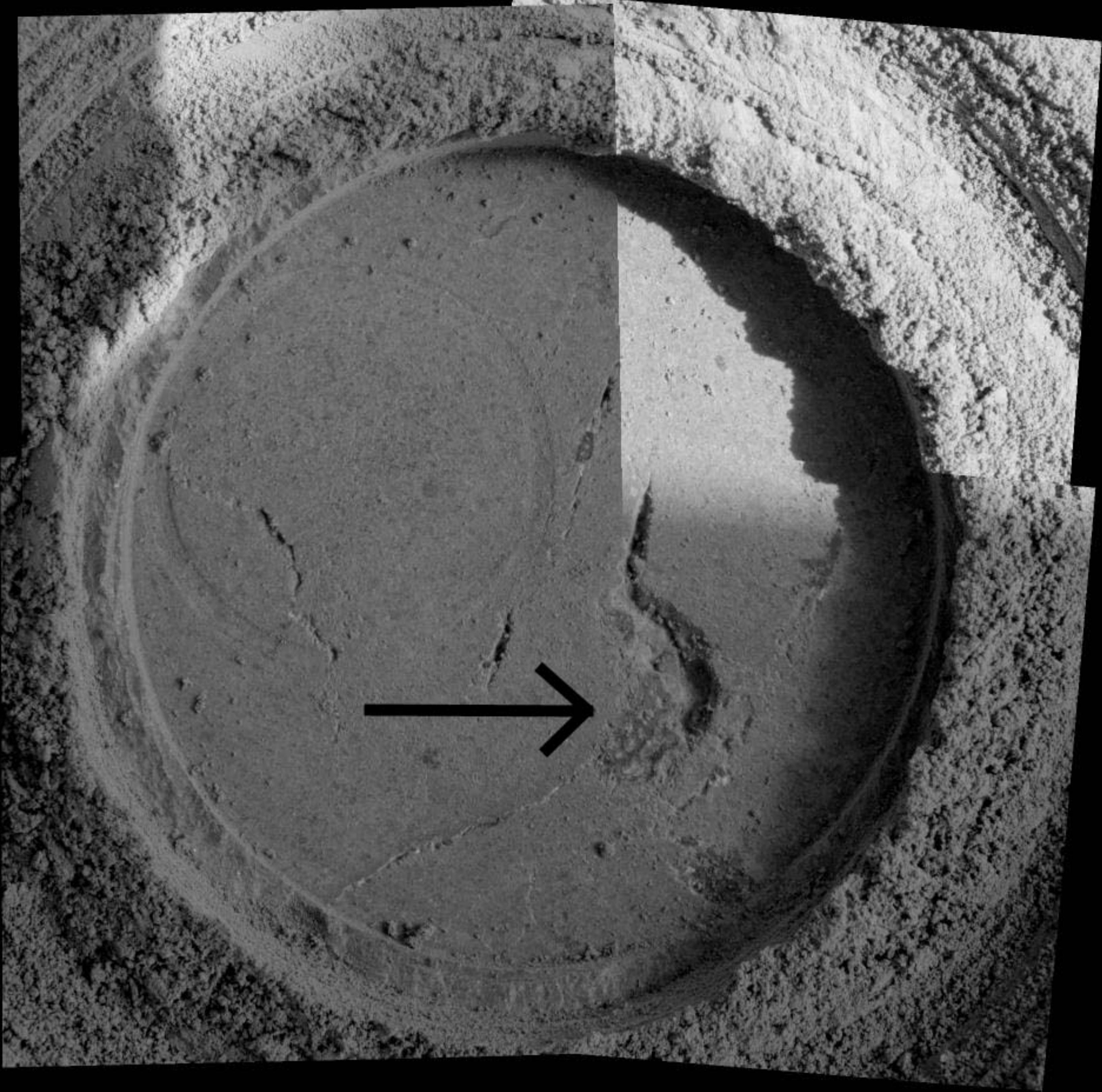




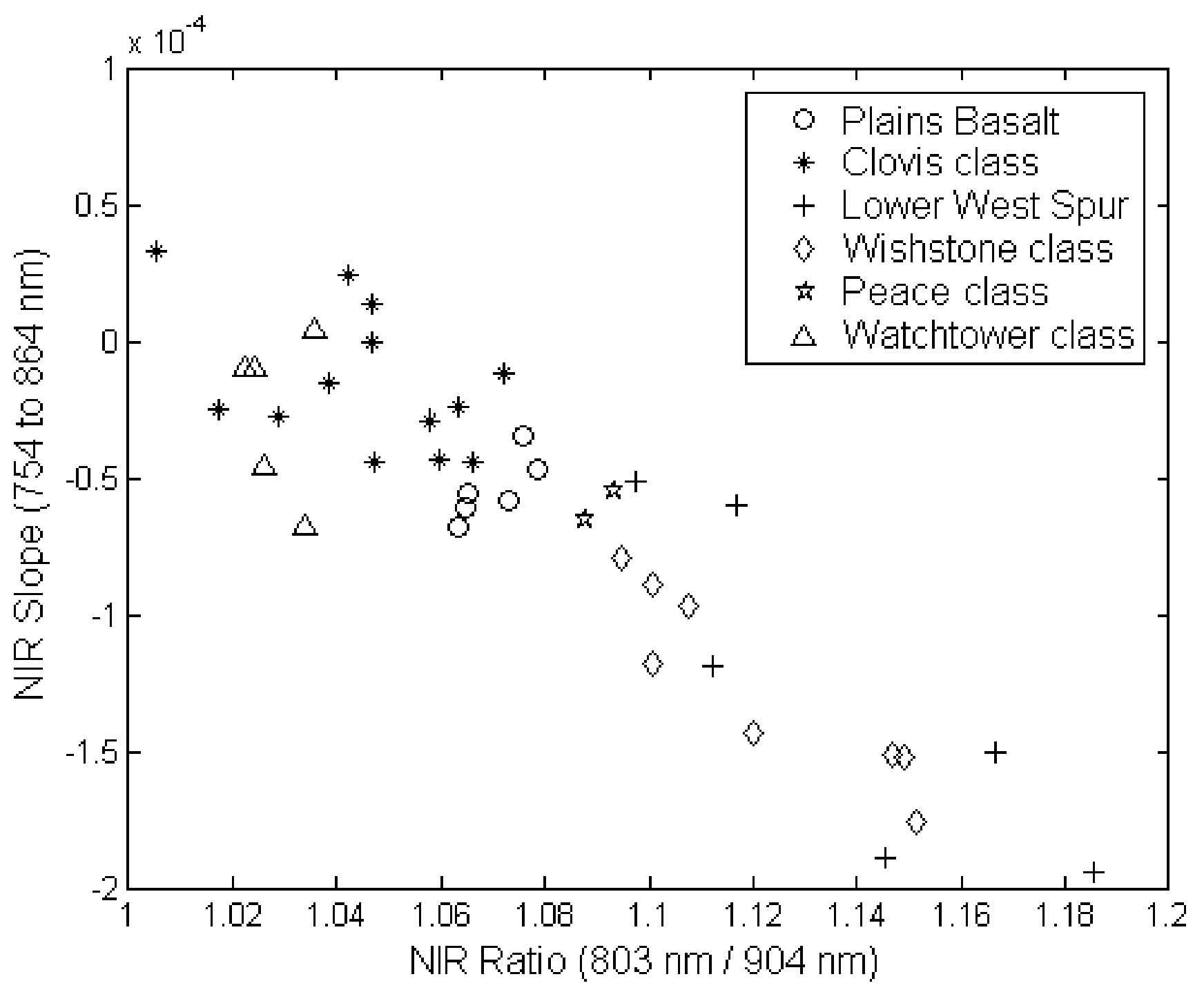




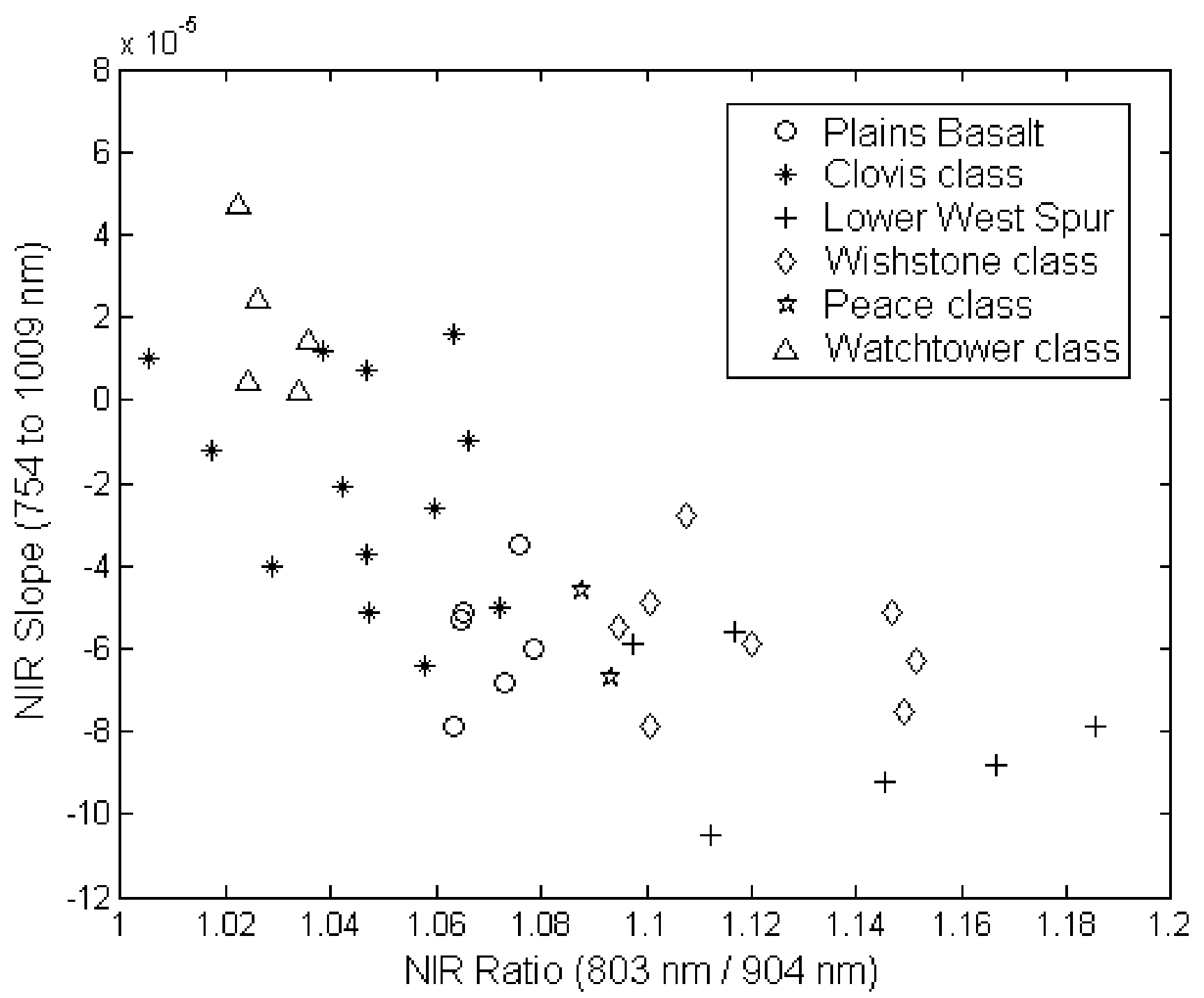




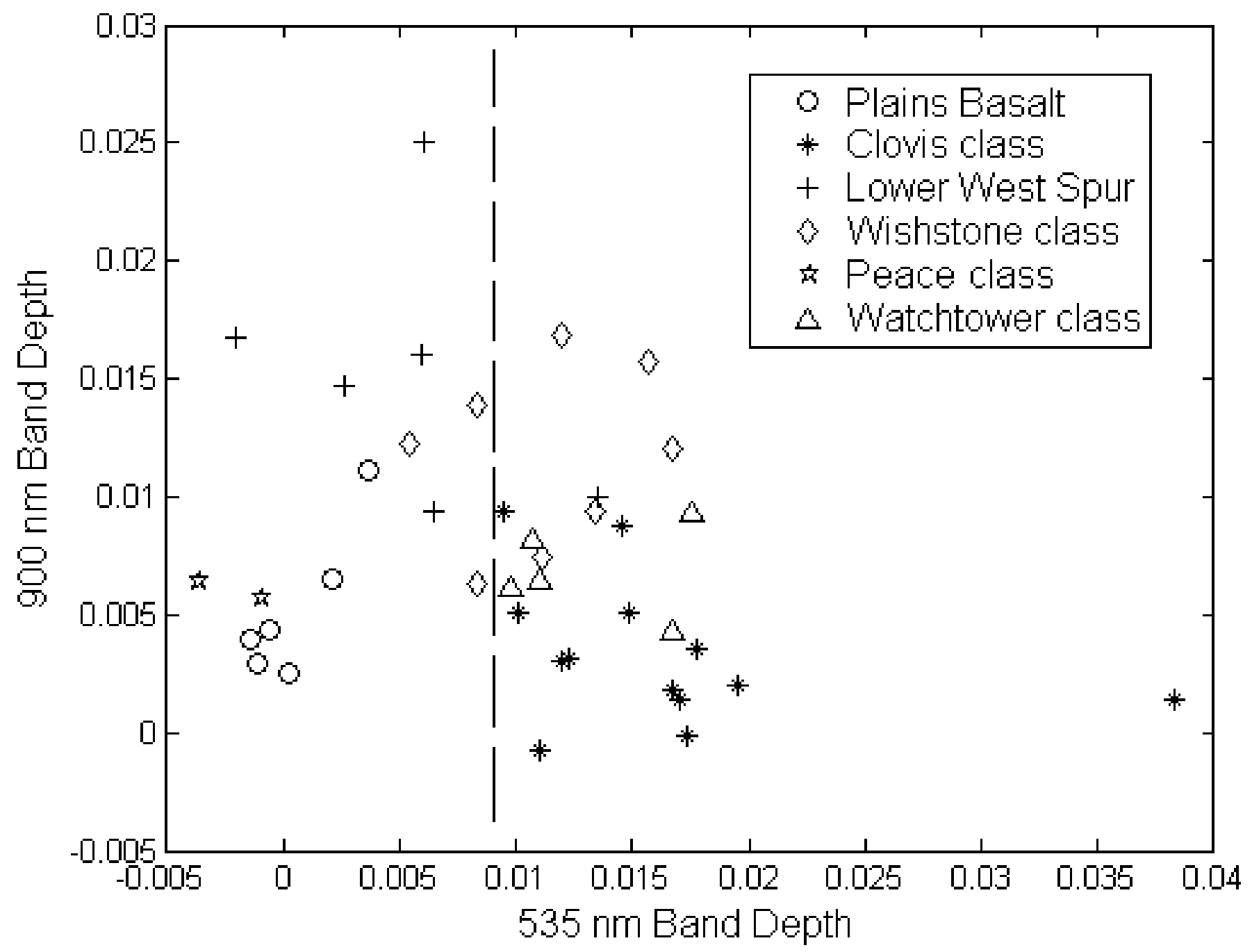




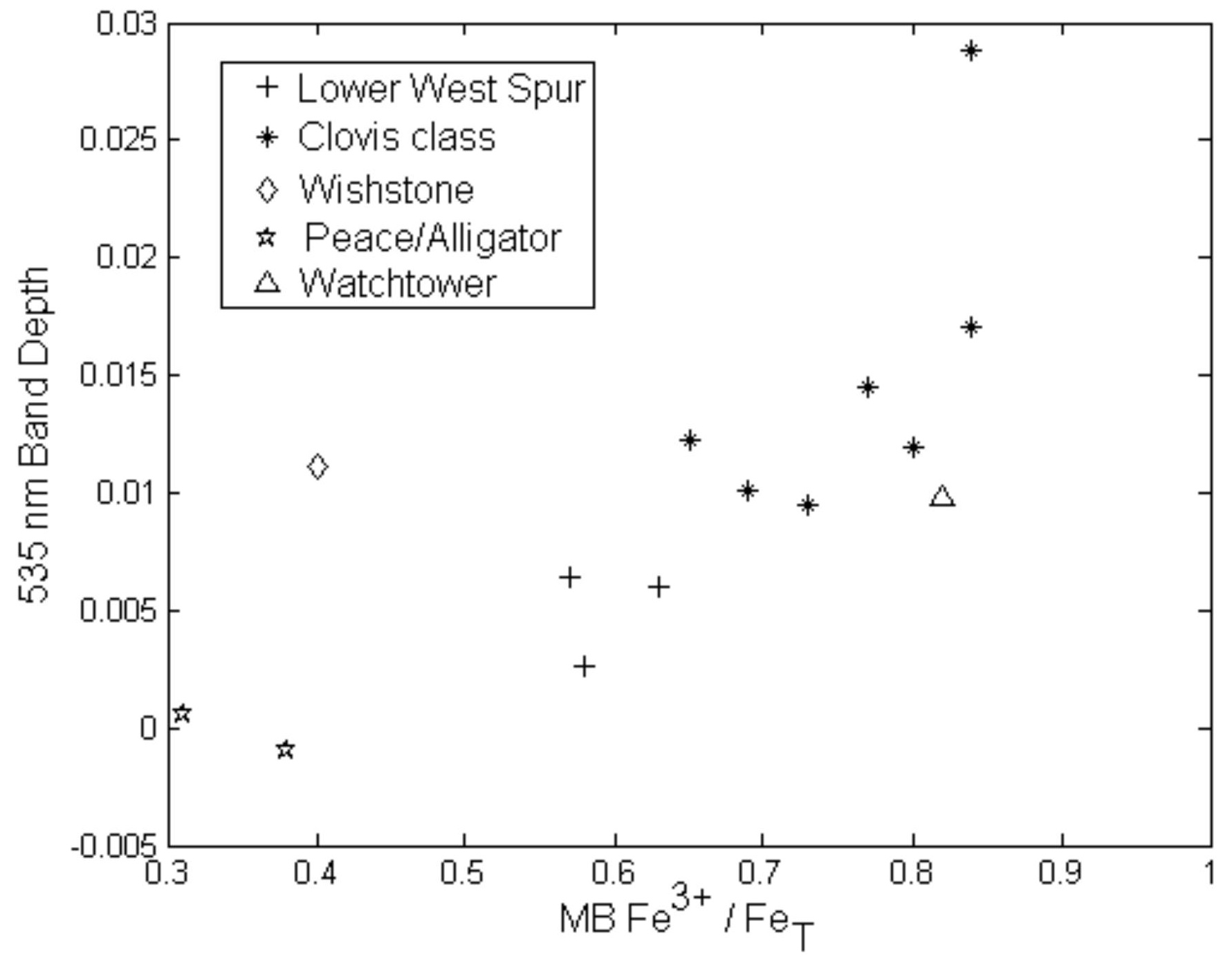




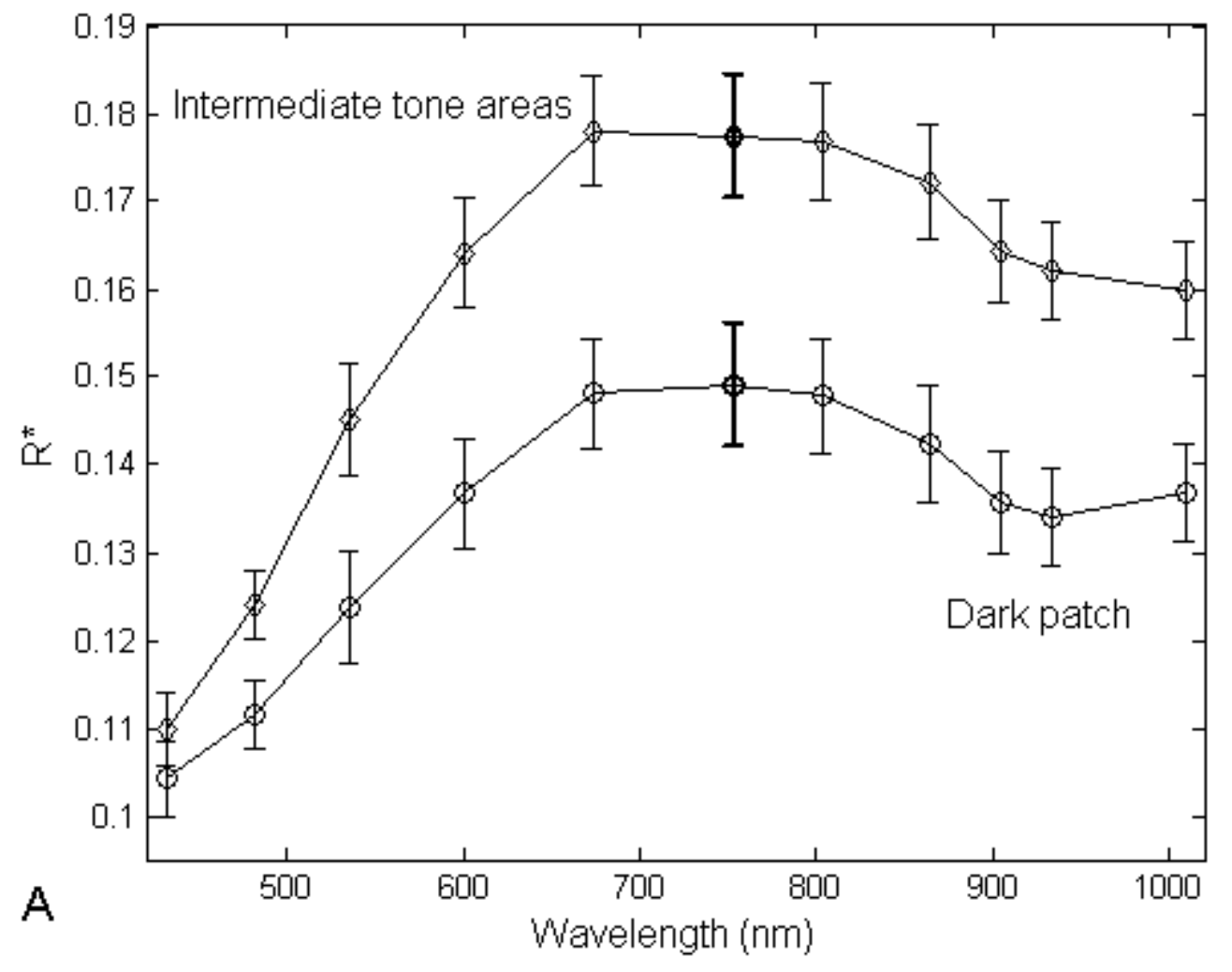




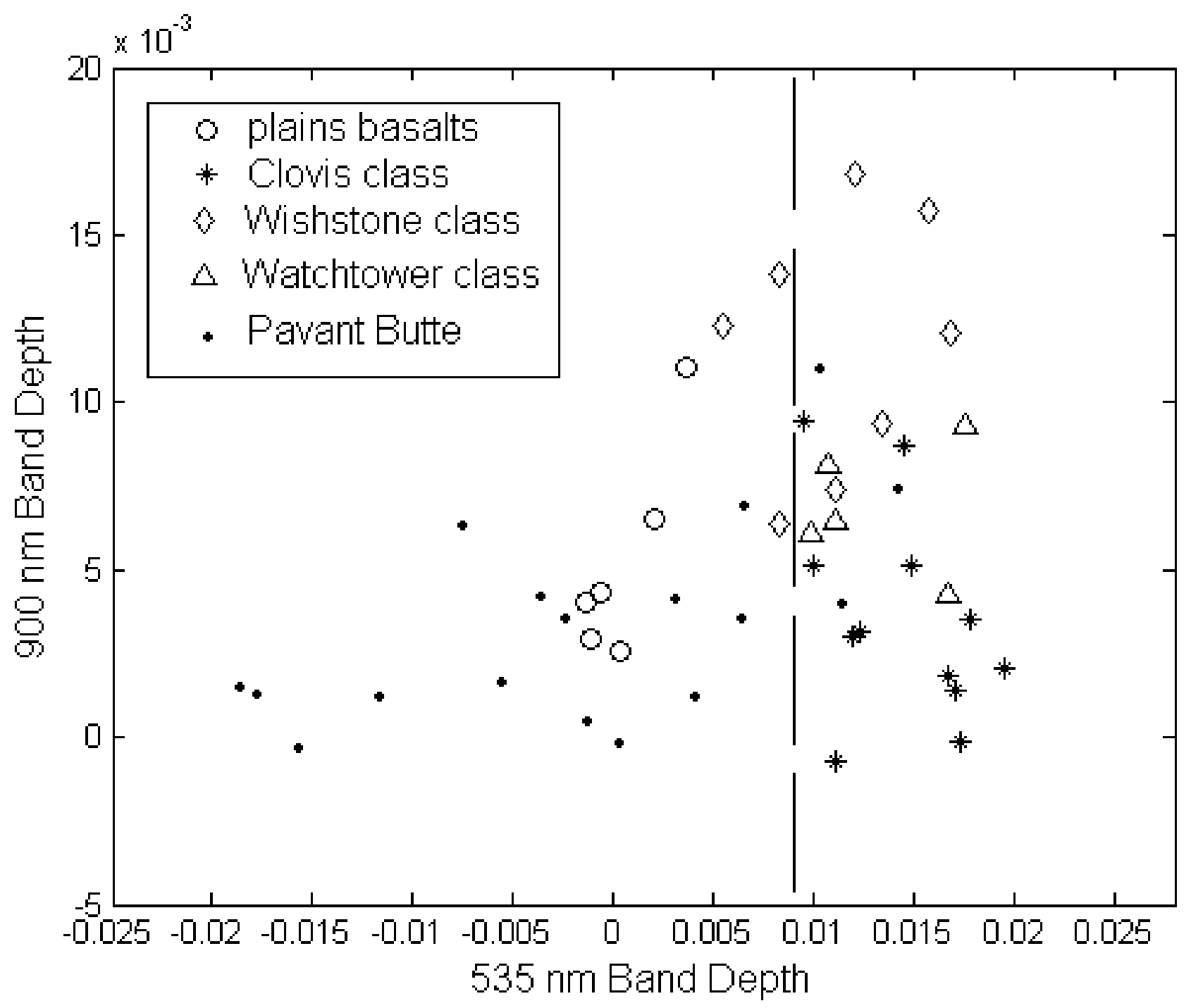


